\title{
Identifying the core bacterial microbiome of hydrocarbon degradation and a shift of dominant methanogenesis pathways in the oil and aqueous phases of petroleum reservoirs of different temperatures from China
}

Zhichao Zhou et al.

Correspondence to: Ji-Dong Gu (jdgu@hku.hk) and Bo-Zhong Mu (bzmu@ecust.edu.cn)

The copyright of individual parts of the supplement might differ from the CC BY 4.0 License. 
Supplementary Data

\subsection{Characterization of geographic properties of sampling reservoirs}

Petroleum fluids samples were collected from eight sampling sites across China covering oilfields of different geological properties. The reservoir and crude oil properties together with the aqueous phase chemical concentration characteristics were listed in Table 1. P1 represents the sample collected from Zhan3-26 well located in Shengli Oilfield. Zhan3 block region in Shengli Oilfield is located in the coastal area from the Yellow River Estuary to the Bohai Sea. It is a medium-high temperature reservoir of fluvial face, made of a thin layer of crossed sand-mudstones, pebbled sandstones and fine sandstones. P2 represents the sample collected from Ba-51 well, which is located in Bayindulan reservoir layer of Erlian Basin, east Inner Mongolia Autonomous Region. It is a reservoir with highly heterogeneous layers, high crude oil viscosity and low formation fluid temperature. It was dedicated to water-flooding, however, due to low permeability and high viscosity of crude oil, displacement efficiency of water-flooding driving process was slowed down along the increase of water-cut rate. P3 and P4 represents samples which were collected from Liuzhong and Qixi blocks from Karamay Oilfield which located about $30 \mathrm{~km}$ to the east of Karamay City. Liuzhong reservoir is located in a pidemont diluvial fan deposit area mainly consisted of conglomerates and uneven gravel bearing sandstones, and is characterized as a reservoir of moderate porosity, high permeability, high crude oil viscosity and high heterogeneity. The reservoir region is distributed in a triangle fault block surrounded by Karamay-Wuerhe fracture belt and northern Baijiantan fracture belt. Qixi reservoir is located at footwall of Baijiantan fracture belt and is characterized as a heterogeneous conglomerate reservoir containing complex pore structures with low porosity and permeability. Both reservoirs from Karamay Oilfield were relatively low temperature reservoirs. P5 represents the sample collected from Wei5 block reservoir located in Gaoyou depression area of Subei Basin (Jiangsu Oilfield). It is a thin sand-mud interbed towards the front margin of a delta region, containing viscous crude oil. Due to its small volume, irregular reserve layers and relatively thin oil-bearing structure, it is difficult to further exploit using commonly applied methods. Many approaches have been carried out on this reservoir, such as cyclic steam stimulation, microorganism and water flood stimulation, etc. P6 represents the sample collected from Gao6 block reservoir located in the middle region of the western slope of Jinhu depression area of Subei Basin. This is a small and thin interbedded reservoir with moderate porosity, low permeability and high inter- and intralayer heterogeneity. P7 represents the sample collected from Xing4 block from Xingbei Oilfield, located in Daqing City. The main reservoir layer is made of lake sedimentary clastic rocks, composed of feldspars and quartz sandstones. The sandstones consist of over half fine sands, second by silty sands, and then medium fine sands. This reservoir is a reservoir comprised of multiple and thin layers, characterized with high porosity and low permeability property. P8 represents the sample collected from Qinying area located in Yangcun fault block. This sampling reservoir is from south part of Jinhu depression area of Subei Basin, and is a newly developed reservoir subjected to production test since 2012. P6 and P8 were both collected from Jinhu depression area from Jiangsu Oilfield and the in situ temperatures were higher than rest samples.

\subsection{Reservoir geophysical properties and physicochemical properties}

Reservoir geophysical properties and ion concentrations of aqueous phase samples were shown in Table 1. The physicochemical properties from P1-P4 aqueous phase samples were derived from the previous work (Wang et al. 2012). P1-P6 samples consist of aqueous and oil phases, while P7 only contains aqueous phase sample and P8 only contains oil phase. P3 and P4 are grouped into low temperature samples; P1, P2, P5 and P7 are grouped into moderate temperature samples; P6 and P8 are characterized as high temperature samples. Meanwhile, P1-P4 samples were $\mathrm{pH}$ neutral, P5-P8 
samples were slightly alkaline. The reservoir general properties, including depth, temperature, $\mathrm{pH}$, effective porosity, average permeability, and crude oil viscosity, were measured by local oilfield management agencies while sampling. All the reservoirs were operated by water flooding for years, aiming to enhance oil recovery efficiency, except for P8, located at Qinying block, Jiangsu Oilfield, a newly exploited site; so that no aqueous phase sample could be extracted from P8 oil-water fluids. Due to very less oil phase sample extracted from oil-water fluids from Xing4 block, Daqing (Xingbei) Oilfield, P7 sample also only contains aqueous phase. The effective porosity indicates percentage of effective interconnected pore space (excluding the porosity which could not benefit connections between pores) in the total volume of rocks, which could facilitate fluids flowing through rocks or sediments. It is an important parameter indicating pore property of reservoirs, reflecting the formation degree and connectivity of a certain reservoir. Average permeability is a measure of general ability of fluids flowing through reservoir layers to the oilwell. Oil viscosity reflects property and composition of crude oil. In general, crude oil with higher oil viscosity means higher content of asphaltenes and resins, and also higher content of long carbon chain hydrocarbons.

\subsection{Diversity of microbial 16S rRNA gene through MiSeq sequencing}

To obtain microbial composition structure from 14 aqueous and oil phase samples, we separately amplified prokaryotic and archaeal 16S rRNA gene from DNA samples. Although, archaeal 16S rRNA gene products could also be amplified from the prokaryotic 16S rRNA gene targeting primer pair, quantities of obtained sequences were limited and biased primers pairs could underestimate certain groups of archaea. Hence, in this study, we firstly sequenced the prokaryotic 16S rRNA gene, and then screened out the archaeal 16S rRNA gene and retained the bacterial 16S rRNA gene library. Finally, after subsampling to make all the library acquire even sequencing depth, each bacterial 16S rRNA gene library consisted of 6100 unique, dereplicated sequences, which through the analysis of QIIME pipeline could achieve good coverage (Good's coverage value within 89.6 to $94.1 \%$ ). Nevertheless, it might be for the reason that low specificity of archaeal 16S rRNA gene primer pair introduced erroneous amplification of non-archaeal sequence and microbial composition was dominated by bacteria, archaeal 16S rRNA gene profile reflected that the majorities of libraries were not archaeal sequences. Consequently, screening out non-archaeal sequences from each library was also conducted, and after sub-sampling, each archaeal 16S rRNA gene library consisted of 760 unique, dereplicated sequences, which through the analysis of QIIME pipeline could achieve Good's coverage values ranging from 93.8 to $98.4 \%$ (Table S1). To analyze composition of methanogens, archaeal 16S rRNA gene libraries were further screened to obtain methanogenic libraries with sequencing depth of 240 for each library, and Good's coverage values ranging from 90.5 to $98.4 \%$. Alpha diversity pattern of bacterial, archaeal, methanogenic $16 \mathrm{~S}$ rRNA gene libraries were summarized into Table S1. From Good's coverage values and rarefaction curves of observed species which have been analyzed through QIIME pipeline for the individual library, it was observed that the majority (generally over 90\%) of underlying species were estimated to be covered. According to the alpha diversity values from bacterial, archaeal and methanogenic libraries, bacterial communities had the largest average Chao1, Shannon and Simpson index value (2043, 5.8, 0.9) while archaeal communities had the second largest average Chao1 value (109.9), methanogenic communities had the smallest average Chaol value (56.2). Archaeal communities had the same level of average Shannon and Simpson values as methanogenic communities (2.6, $0.6 ; 2.3,0.6$ ). Whereas, in terms of coefficient of variation of the above three indices (standard deviation over average value), the bacterial community acquired lower variation level of the three indices $(2.4 \%, 13.5 \%, 5.3 \%)$, while, the archaeal and methanogenic communities acquired higher variation level of the three indices $(51.5 \%, 38.1 \%, 33 \% ; 65.9 \%, 43.3 \%, 40.5 \%)$. It is indicative that even though archaeal/methanogenic communities of 14 aqueous and oil samples show lower diverse patterns than bacterial communities, their intra-sample variations are larger than those of bacterial communities. 


\subsection{Taxonomic and compositional profiles of microbial 16S rRNA gene through MiSeq sequencing}

The open-reference OTU picking method implemented in QIIME assures that all sequences are divided into genus level OTUs with the guidance of genus level reference sequences, thus offers an exhaustive OTU classification (Rideout et al. 2014). Average bacterial sequences unclassified into known genera could account for $31.91 \%$; and average archaeal sequences unclassified into known genera could account for $9.59 \%$, while the percentage of average methanogenic sequences unclassified into known genera was even as low as $0.38 \%$ (Table S2). Taxonomic compositional profiles of 14 aqueous and oil phase samples revealed that on the genus level, 931 bacterial genera and 56 archaeal genera were obtained among all the samples. There were 36 bacterial genera with average abundance percentage over $0.5 \%$ amongst all the bacterial communities, and there were 14 archaeal genera with the average abundance percentage over $0.5 \%$ amongst all the archaeal communities. The most abundant five genera among bacterial communities were Pseudomonas (16.12\%), Acinetobacter (9.94\%), uncultured genus within Hydrogenophilaceae (5.44\%), Proteiniphilum (3.06\%) and Marinobacter (2.91\%). The most abundant five genera among archaeal communities were Methanosaeta (42.3\%), Methanothermobacter (9.69\%), Methanolobus (9.07\%), Methanocalculus (8.05\%) and Methanoculleus (5.01\%) (Table S3).

\subsection{Quantitation of $m c r A$ gene abundance}

Quantity units of $m c r A$ gene abundance of aqueous and oil samples were gene copy numbers per microliter water sample and gene copy numbers per gram oil sample, respectively (Figure $\mathrm{S} 1$ ). The $m c r A$ gene copies of all samples from this study varied substantially from $2.5 \times 10^{2}$ copies/g in P8O to $2.9 \times 10^{7}$ copies/g in $\mathrm{P} 3 \mathrm{O}$ sample. The $m c r A$ gene abundances in low temperature samples (P3 and $\mathrm{P} 4)$ were the highest among all the samples in terms of both aqueous and oil phases, ranging from $2.8 \times 10^{5}$ to $4.3 \times 10^{5}$ copies $/ \mathrm{ml}$ in aqueous phase, and $6.4 \times 10^{6}$ to $2.9 \times 10^{7}$ copies $/ \mathrm{g}$ in oil phase. For moderate temperature samples (P1, P2, P5 and P7), the mcrA gene abundance among aqueous samples was ranging from $1.2 \times 10^{3}$ copies $/ \mathrm{ml}$ in P5A to $3.3 \times 10^{5}$ copies $/ \mathrm{ml}$ in P1A, while the highest $m c r A$ gene abundance among oil samples was ranging from $1.7 \times 10^{3}$ copies $/ \mathrm{g}$ in $\mathrm{P} 5 \mathrm{O}$ to $1.1 \times 10^{6}$ copies/g in $\mathrm{P} 1 \mathrm{O}$. For high temperature samples ( $\mathrm{P} 6$ and $\mathrm{P} 8$ ), the $m c r A$ gene abundance of aqueous sample was $9.2 \times 10^{3}$ copies $/ \mathrm{ml}$ in $\mathrm{P} 6 \mathrm{~A}$, and the $m c r A$ gene abundance of oil samples was ranging from $2.5 \times 10^{2}$ copies/g in $\mathrm{P} 8 \mathrm{O}$ to $2.8 \times 10^{4}$ copies/g in $\mathrm{P} 6 \mathrm{O}$. Within aqueous and oil phases of one individual sample, the numerical value of $m c r A$ gene copy number in oil phase was generally one to two orders of magnitude larger than that in aqueous phase. 


\section{Supplementary Figures and Tables}

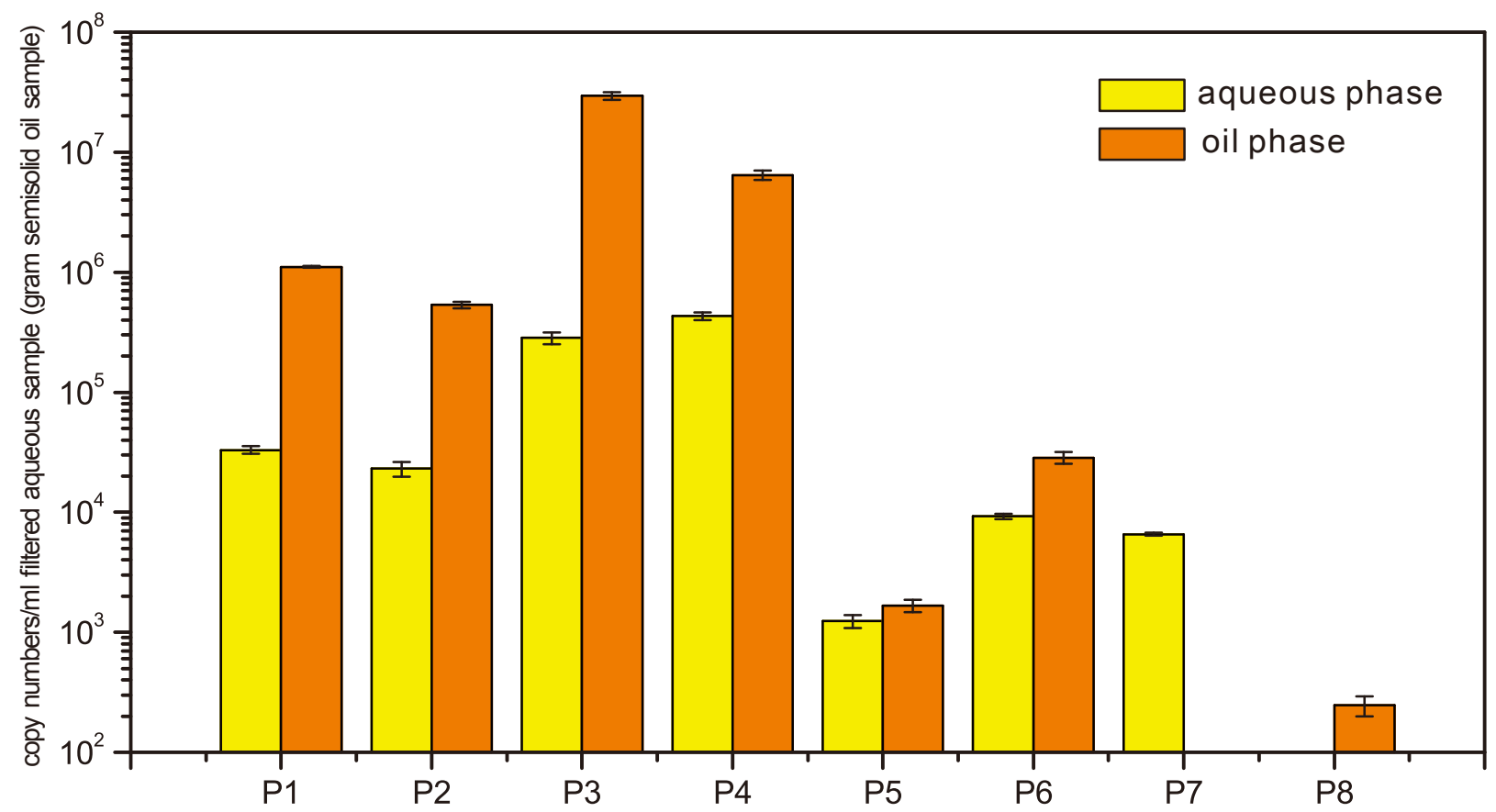

Figure S1. $m c r A$ gene abundance of 14 aqueous and oil phase samples. Vertical coordinate was drawn in lognormalized label. The aqueous samples $m c r A$ gene quantities were gene copy numbers/ml filtered aqueous sample; the oil samples $m c r A$ gene quantities were gene copy numbers/gram semisolid oil sample. 


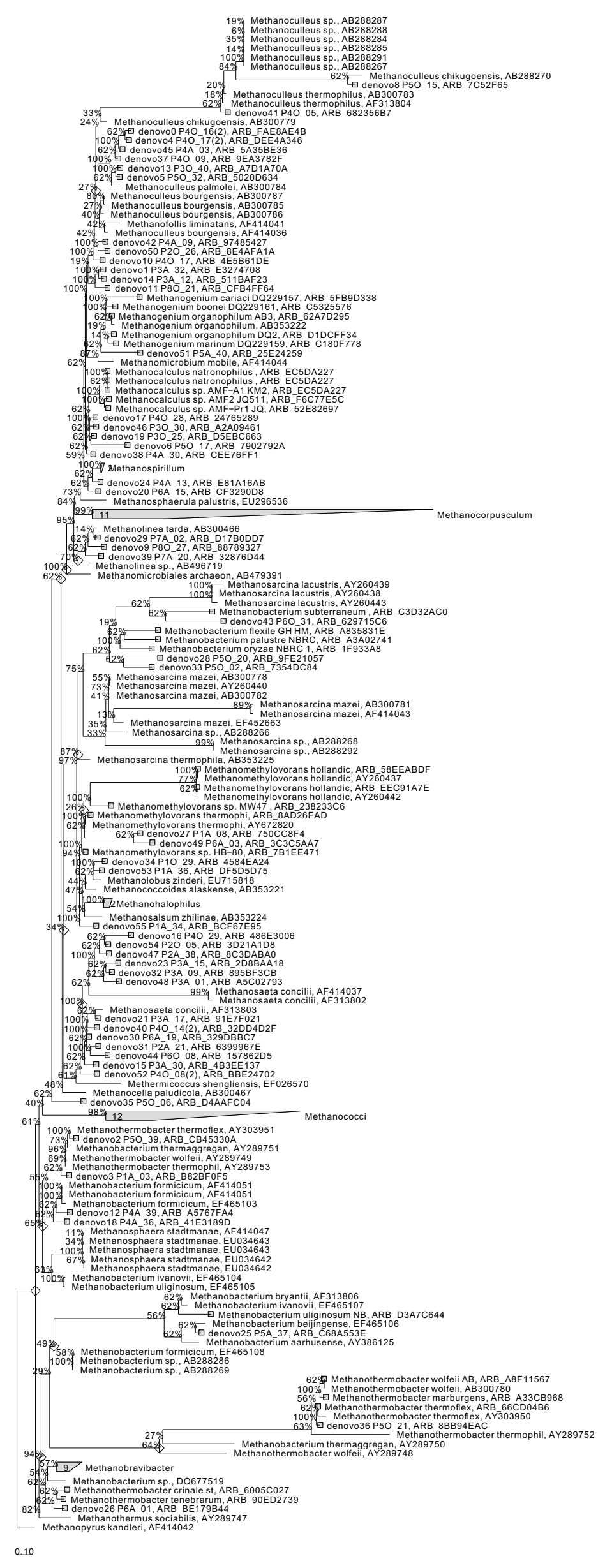

Figure S2. Phylogenetic tree based on clone library $m c r A$ gene and reference gene sequences. The OTU representative $m c r A$ gene clone sequences were obtained by 0.05 cutoff on nucleotide level, and then inserted into $m c r A$ gene ARB database by maximum parsimony method without changing the initial tree topology.(mcrA gene ARB database: http://www.mpimarburg.mpg.de/downloads/conrad/) 
a

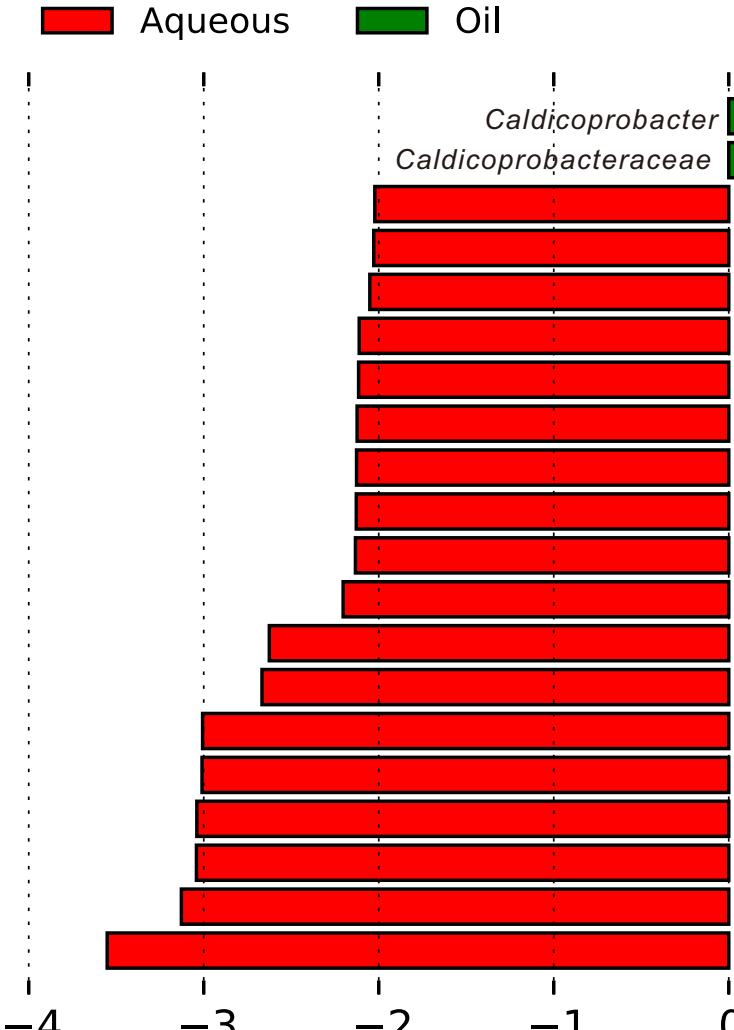

Bradyrhizobium

Acidobacteriaceae Subgroup 1; uncultured

Bradyrhizobiaceae

Acidimicrobiaceae

Acidobacteria;Subgroup:17

Sphingobaciteriales; PHO'S_HE51;unciultured_bacterium

Christenseriellaceae

Christensenellaceae; unciltured

Sphingobaóteriales; PHO'S_HE51

Cytophagales

Acidobacteria;Acidobactieria

Acidobacteria

Exiguobacterium

Bacillales; Fiamily XII

Bacillales

Bacilli

Novosphingobium

Firmicutes:

0

1

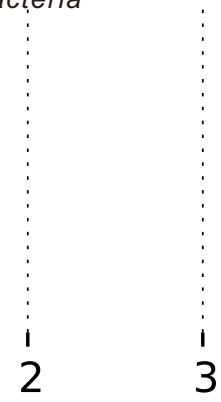

b

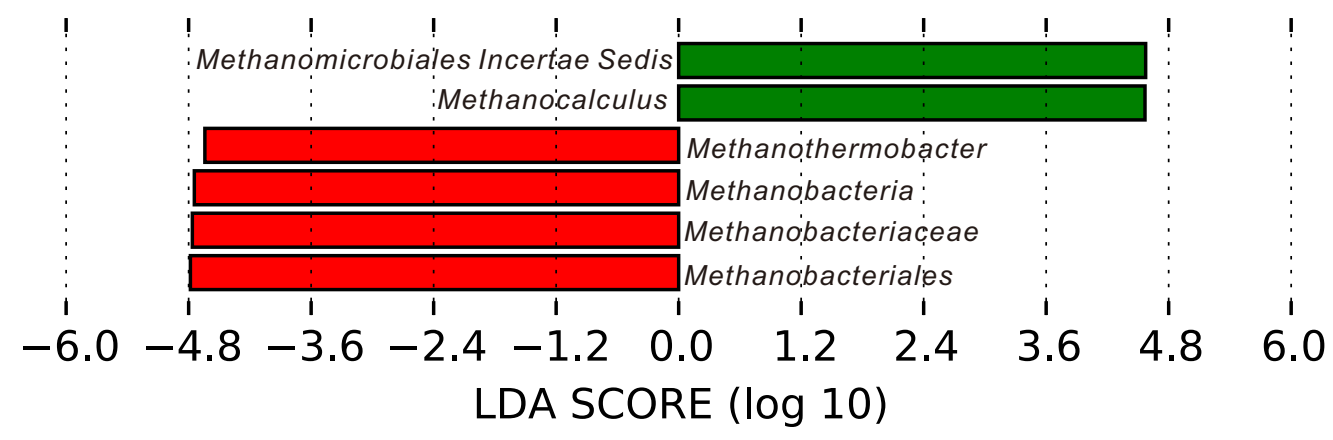

Figure S3. Differentially distributed features of microbial taxon abundance in aqueous and oil phases. LEfSe analysis with LDA effect score was applied. (a) bacterial community feature; (b) archaeal community feature. 


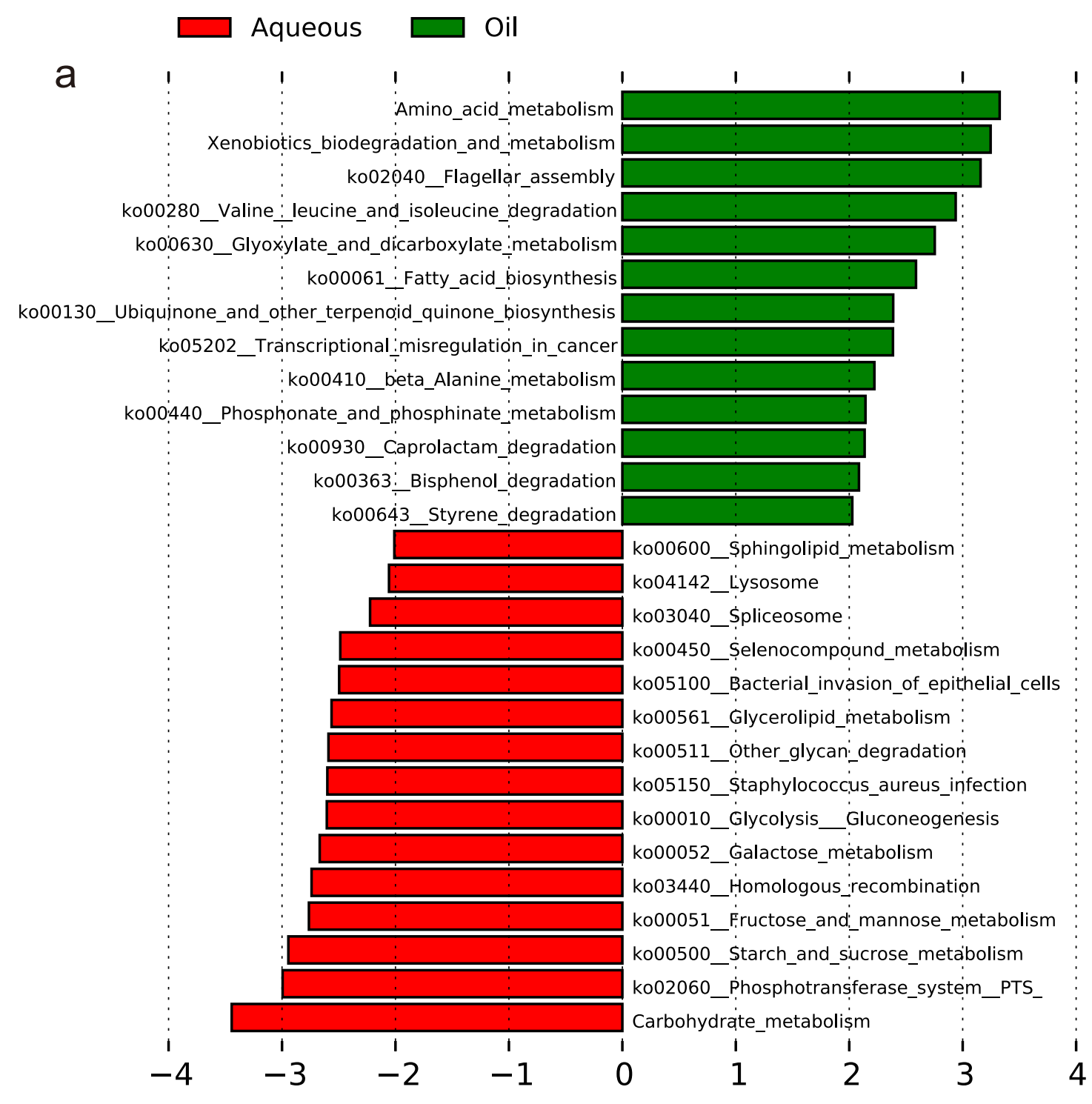

b

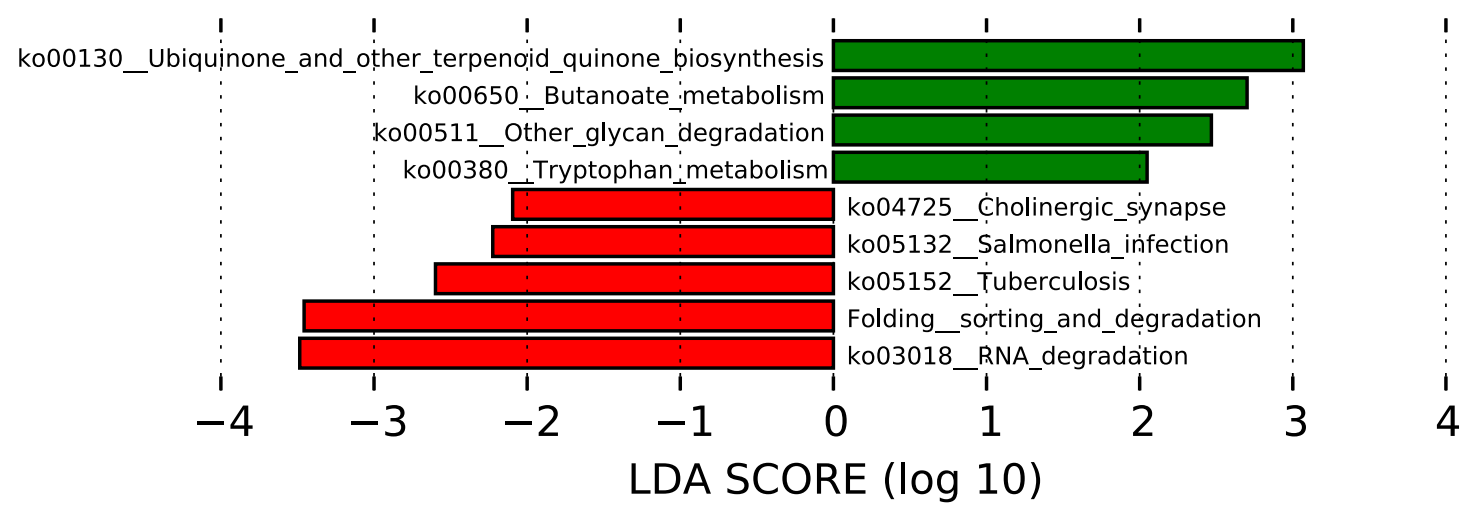

Figure S4. Differentially distributed feature of functional profiles in aqueous and oil phases. LEfSe analysis results based on the predicted functional profiles by Tax4Fun. (a) bacterial community feature; (b) archaeal community feature. 
Table S1. Alpha diversity values of aqueous and oil phase samples including bacterial, archaeal, methanogenic microorganism communities based on MiSeq archaeal 16S rRNA gene sequencing, methanogenic 16S rRNA gene clone library and $m c r A$ gene clone library construction.

Bacteria (MiSeq)

\begin{tabular}{|c|c|c|c|c|c|c|c|}
\hline SampleID & Seqs/Sample & PD_whole_tree & Chao1 & Good's_coverage & observed_species & Shannon & Simpson \\
\hline P1A & 6100 & 39.222 & 1951.164 & 0.918 & 742.2 & 5.868 & 0.939 \\
\hline $\mathrm{P} 1 \mathrm{O}$ & 6100 & 32.782 & 1378.172 & 0.941 & 552.6 & 4.727 & 0.873 \\
\hline $\mathrm{P} 2 \mathrm{~A}$ & 6100 & 39.311 & 2137.544 & 0.915 & 720.4 & 4.886 & 0.872 \\
\hline $\mathrm{P} 2 \mathrm{O}$ & 6100 & 36.549 & 1869.683 & 0.923 & 669.6 & 5.003 & 0.875 \\
\hline P3A & 6100 & 50.028 & 2183.686 & 0.903 & 921.3 & 6.194 & 0.932 \\
\hline $\mathrm{P} 3 \mathrm{O}$ & 6100 & 48.894 & 2098.391 & 0.903 & 972.5 & 6.653 & 0.941 \\
\hline P4A & 6100 & 43.85 & 2081.336 & 0.913 & 794.5 & 5.475 & 0.876 \\
\hline $\mathrm{P} 4 \mathrm{O}$ & 6100 & 45.632 & 2156.457 & 0.906 & 843.4 & 4.765 & 0.794 \\
\hline P5A & 6100 & 45.792 & 2468.217 & 0.9 & 891.2 & 6.499 & 0.961 \\
\hline $\mathrm{P} 5 \mathrm{O}$ & 6100 & 36.263 & 2112.554 & 0.923 & 669.7 & 5.396 & 0.915 \\
\hline P6A & 6100 & 39.937 & 2006.069 & 0.916 & 769.7 & 6.157 & 0.941 \\
\hline P6O & 6100 & 40.756 & 2196.376 & 0.91 & 826.6 & 6.5 & 0.959 \\
\hline P7A & 6100 & 49.66 & 2195.145 & 0.896 & 1032.6 & 7.2 & 0.969 \\
\hline $\mathrm{P} 8 \mathrm{O}$ & 6100 & 39.205 & 1767.685 & 0.924 & 726.8 & 5.73 & 0.924 \\
\hline \multicolumn{8}{|c|}{ Archaea (MiSeq) } \\
\hline SampleID & Seqs/Sample & PD_whole_tree & Chao1 & Good's_coverage & observed_species & Shannon & Simpson \\
\hline $\mathrm{P} 1 \mathrm{~A}$ & 760 & 3.089 & 262.751 & 0.938 & 77.4 & 3.747 & 0.86 \\
\hline $\mathrm{P} 10$ & 760 & 2.265 & 39.79 & 0.984 & 26.7 & 1.774 & 0.512 \\
\hline $\mathrm{P} 2 \mathrm{~A}$ & 760 & 2.7 & 66.741 & 0.977 & 42.5 & 2.297 & 0.557 \\
\hline $\mathrm{P} 2 \mathrm{O}$ & 760 & 2.697 & 102.594 & 0.958 & 51.7 & 1.529 & 0.327 \\
\hline $\mathrm{P} 3 \mathrm{~A}$ & 760 & 2.615 & 96.15 & 0.966 & 63 & 4.121 & 0.896 \\
\hline $\mathrm{P} 3 \mathrm{O}$ & 760 & 4.15 & 144.067 & 0.948 & 58.7 & 2.263 & 0.584 \\
\hline $\mathrm{P} 4 \mathrm{~A}$ & 760 & 2.733 & 125.857 & 0.952 & 65.4 & 2.791 & 0.668 \\
\hline $\mathrm{P} 4 \mathrm{O}$ & 760 & 3.542 & 147.413 & 0.94 & 84.2 & 3.862 & 0.843 \\
\hline P5A & 760 & 2.732 & 130.623 & 0.958 & 56.3 & 3.262 & 0.829 \\
\hline $\mathrm{P} 5 \mathrm{O}$ & 760 & 2.714 & 99.733 & 0.96 & 61.7 & 3.861 & 0.886 \\
\hline P6A & 760 & 2.105 & 108.36 & 0.968 & 35.8 & 1.282 & 0.306 \\
\hline P6O & 760 & 2.288 & 100.186 & 0.962 & 50 & 2.75 & 0.746 \\
\hline P7A & 760 & 2.569 & 91.164 & 0.962 & 50.7 & 1.735 & 0.393 \\
\hline $\mathrm{P} 8 \mathrm{O}$ & 760 & 1.682 & 23.15 & 0.992 & 15.9 & 1.494 & 0.518 \\
\hline \multicolumn{8}{|c|}{ Methanogen (MiSeq) } \\
\hline SampleID & Seqs/Sample & PD_whole_tree & Chao1 & Good's_coverage & observed_species & Shannon & Simpson \\
\hline $\mathrm{P} 1 \mathrm{~A}$ & 240 & 1.135 & 71.814 & 0.911 & 36.2 & 3.391 & 0.846 \\
\hline $\mathrm{P} 1 \mathrm{O}$ & 240 & 0.3 & 15.65 & 0.984 & 12.9 & 1.695 & 0.508 \\
\hline $\mathrm{P} 2 \mathrm{~A}$ & 240 & 1.16 & 32.463 & 0.951 & 21.5 & 1.492 & 0.361 \\
\hline $\mathrm{P} 2 \mathrm{O}$ & 240 & 0.98 & 60.625 & 0.928 & 25.3 & 1.506 & 0.349 \\
\hline P3A & 240 & 0.918 & 63.343 & 0.926 & 39.6 & 3.932 & 0.881 \\
\hline $\mathrm{P} 3 \mathrm{O}$ & 240 & 1.288 & 107.15 & 0.926 & 24.6 & 2.1 & 0.602 \\
\hline $\mathrm{P} 4 \mathrm{~A}$ & 240 & 1.156 & 144.65 & 0.905 & 31.9 & 2.435 & 0.621 \\
\hline $\mathrm{P} 4 \mathrm{O}$ & 240 & 1.356 & 62.492 & 0.926 & 32.6 & 3.336 & 0.823 \\
\hline P5A & 240 & 1.242 & 37.325 & 0.942 & 25.7 & 2.72 & 0.756 \\
\hline P5O & 240 & 1.393 & 83.467 & 0.916 & 34 & 3.559 & 0.874 \\
\hline P6A & 240 & 0.986 & 23.1 & 0.971 & 12.9 & 1.049 & 0.277 \\
\hline P6O & 240 & 1.228 & 37.39 & 0.95 & 24 & 2.649 & 0.733 \\
\hline P7A & 240 & 0.865 & 31.808 & 0.954 & 21.8 & 1.547 & 0.375 \\
\hline $\mathrm{P} 8 \mathrm{O}$ & 240 & 0.825 & 15.1 & 0.98 & 9.8 & 0.798 & 0.218 \\
\hline
\end{tabular}


Methanogen (Methanogenic 16S rRNA gene clone library)

\begin{tabular}{|c|c|c|c|c|c|c|c|}
\hline SampleID & Seqs/Sample & PD_whole_tree & Chao1 & Good's_coverage & observed_species & Shannon & Simpson \\
\hline $\mathrm{P} 1 \mathrm{~A}$ & 28 & 1.167 & 8.5 & 0.893 & 7 & 2.132 & 0.689 \\
\hline $\mathrm{P} 1 \mathrm{O}$ & 28 & 1.101 & 10 & 0.857 & 7 & 1.84 & 0.589 \\
\hline $\mathrm{P} 2 \mathrm{~A}$ & 28 & 0.997 & 7.5 & 0.929 & 7 & 2.277 & 0.724 \\
\hline $\mathrm{P} 2 \mathrm{O}$ & 28 & 0.415 & 6.333 & 0.929 & 6 & 1.698 & 0.554 \\
\hline P3A & 28 & 0.337 & 8.333 & 0.929 & 8 & 2.564 & 0.781 \\
\hline P3O & 28 & 0.305 & 3 & 0.964 & 3 & 1.139 & 0.503 \\
\hline $\mathrm{P} 4 \mathrm{~A}$ & 28 & 0.519 & 12.5 & 0.821 & 10 & 2.52 & 0.717 \\
\hline $\mathrm{P} 4 \mathrm{O}$ & 28 & 0.472 & 6 & 1 & 6 & 2.296 & 0.758 \\
\hline P5A & 28 & 1.314 & 13.333 & 0.821 & 10 & 2.846 & 0.827 \\
\hline $\mathrm{P} 5 \mathrm{O}$ & 28 & 0.472 & 4 & 1 & 4 & 1.662 & 0.64 \\
\hline P6A & 28 & 1.078 & 5 & 0.964 & 5 & 1.67 & 0.582 \\
\hline P6O & 28 & 1.051 & 13 & 0.857 & 7 & 2.032 & 0.671 \\
\hline P7A & 28 & 0.238 & 2 & 1 & 2 & 0.592 & 0.245 \\
\hline P8O & 28 & 1.267 & 8 & 0.929 & 7 & 2.503 & 0.801 \\
\hline \multicolumn{8}{|c|}{ Methanogen ( mcrA gene clone library) } \\
\hline SampleID & Seqs/Sample & PD_whole_tree & Chao1 & Good's_coverage & observed_species & Shannon & Simpson \\
\hline $\mathrm{P} 1 \mathrm{~A}$ & 23 & 10 & 0.826 & 8 & 2.435 & 0.756 & 0.756 \\
\hline $\mathrm{P} 1 \mathrm{O}$ & 23 & 5 & 0.957 & 5 & 1.684 & 0.582 & 0.582 \\
\hline $\mathrm{P} 2 \mathrm{~A}$ & 23 & 8 & 0.87 & 5 & 1.578 & 0.582 & 0.582 \\
\hline $\mathrm{P} 2 \mathrm{O}$ & 23 & 6 & 0.913 & 5 & 1.808 & 0.658 & 0.658 \\
\hline P3A & 23 & 9.6 & 0.87 & 9 & 2.729 & 0.794 & 0.794 \\
\hline $\mathrm{P} 3 \mathrm{O}$ & 23 & 17 & 0.783 & 7 & 2.036 & 0.681 & 0.681 \\
\hline P4A & 23 & 57 & 0.565 & 12 & 2.975 & 0.813 & 0.813 \\
\hline $\mathrm{P} 4 \mathrm{O}$ & 23 & 26 & 0.739 & 11 & 3.208 & 0.877 & 0.877 \\
\hline P5A & 23 & 9 & 0.87 & 8 & 2.595 & 0.794 & 0.794 \\
\hline P5O & 23 & 19 & 0.696 & 12 & 3.262 & 0.87 & 0.87 \\
\hline P6A & 23 & 8 & 0.87 & 7 & 2.255 & 0.733 & 0.733 \\
\hline P6O & 23 & 6.5 & 0.913 & 6 & 2.086 & 0.699 & 0.699 \\
\hline P7A & 23 & 7.333 & 0.913 & 7 & 2.351 & 0.745 & 0.745 \\
\hline P8O & 23 & 6.5 & 0.87 & 5 & 1.173 & 0.374 & 0.374 \\
\hline
\end{tabular}


Table S2. Unclassified sequences percentage in each taxon level based on QIIME software applying SILVA compatible 119 release SSURef database as reference. a) bacterial community table and chart; b) archaeal community table and chart.

a

\begin{tabular}{|c|c|c|c|c|c|c|c|c|c|c|c|c|c|c|c|}
\hline & P1A & P10 & P2A & P2O & P3A & P3O & P4A & P4O & P5A & P50 & P6A & P60 & P7A & P8O & average \\
\hline phylum & $0.00 \%$ & $0.00 \%$ & $0.00 \%$ & $0.00 \%$ & $0.00 \%$ & $0.00 \%$ & $0.00 \%$ & $0.00 \%$ & $0.00 \%$ & $0.00 \%$ & $0.00 \%$ & $0.00 \%$ & $0.00 \%$ & $0.00 \%$ & $0.00 \%$ \\
\hline class & $0.38 \%$ & $0.15 \%$ & $0.44 \%$ & $0.23 \%$ & $6.32 \%$ & $2.85 \%$ & $1.43 \%$ & $2.92 \%$ & $0.41 \%$ & $0.20 \%$ & $1.67 \%$ & $0.84 \%$ & $5.18 \%$ & $3.65 \%$ & $1.90 \%$ \\
\hline order & $0.69 \%$ & $0.29 \%$ & $1.28 \%$ & $5.59 \%$ & $7.01 \%$ & $4.05 \%$ & $1.77 \%$ & $3.24 \%$ & $0.95 \%$ & $0.70 \%$ & $3.26 \%$ & $6.19 \%$ & $5.96 \%$ & $4.34 \%$ & $3.24 \%$ \\
\hline family & $3.06 \%$ & $17.66 \%$ & $4.39 \%$ & $7.72 \%$ & $12.37 \%$ & $9.52 \%$ & $9.71 \%$ & $6.62 \%$ & $4.16 \%$ & 3.98 & $5.52 \%$ & $8.40 \%$ & $9.11 \%$ & $7.75 \%$ & $7.86 \%$ \\
\hline genus & $11.53 \%$ & $61.99 \%$ & $13.50 \%$ & $13.76 \%$ & $33.08 \%$ & $63.37 \%$ & $23.53 \%$ & $79.77 \%$ & $27.42 \%$ & $23.05 \%$ & $25.29 \%$ & $31.65 \%$ & $23.69 \%$ & $15.17 \%$ & $31.91 \%$ \\
\hline
\end{tabular}

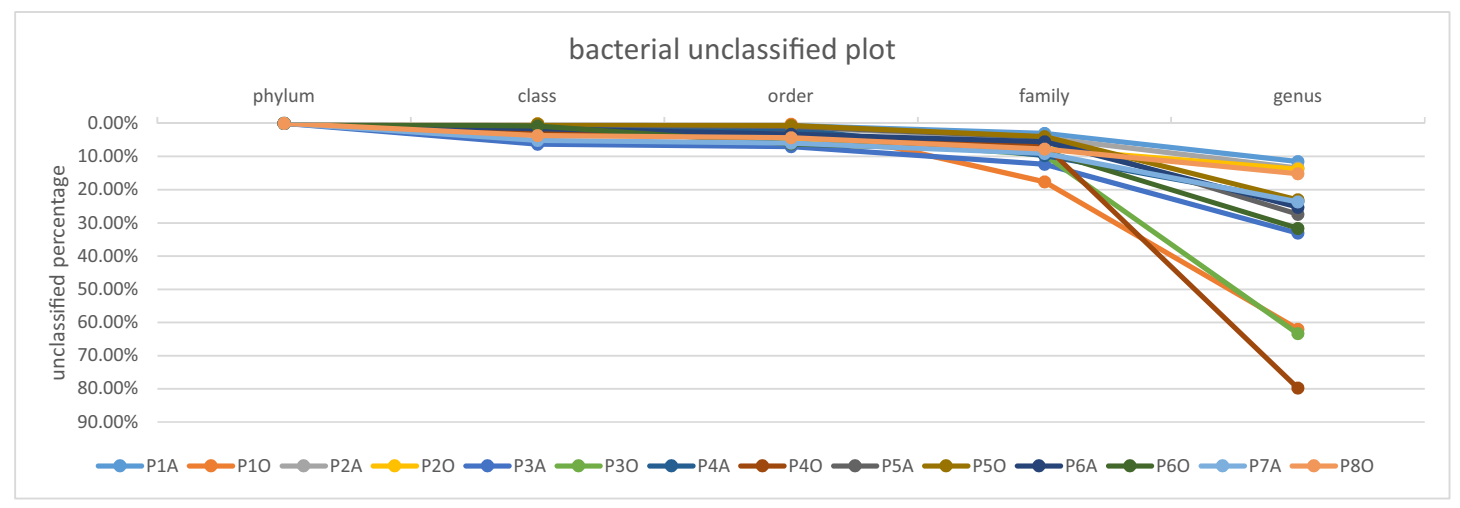

b

\begin{tabular}{|lcccccccccccrrrr} 
& P1A & P10 & P2A & P20 & P3A & P30 & P4A & P40 & P5A & P50 & P6A & P60 & P7A & P80 & average \\
phylum & $0.00 \%$ & $0.00 \%$ & $0.00 \%$ & $0.00 \%$ & $0.00 \%$ & $0.00 \%$ & $0.00 \%$ & $0.00 \%$ & $0.00 \%$ & $0.00 \%$ & $0.00 \%$ & $0.00 \%$ & $0.00 \%$ & $0.00 \%$ & $0.00 \%$ \\
\hline class & $0.00 \%$ & $0.00 \%$ & $0.00 \%$ & $0.00 \%$ & $0.00 \%$ & $0.00 \%$ & $0.00 \%$ & $0.00 \%$ & $0.00 \%$ & $0.00 \%$ & $0.00 \%$ & $0.00 \%$ & $0.00 \%$ & $0.00 \%$ & $0.00 \%$ \\
\hline order & $0.13 \%$ & $0.13 \%$ & $0.00 \%$ & $0.00 \%$ & $0.13 \%$ & $0.00 \%$ & $0.00 \%$ & $0.00 \%$ & $0.26 \%$ & $0.00 \%$ & $0.26 \%$ & $0.00 \%$ & $0.00 \%$ & $0.00 \%$ & $0.07 \%$ \\
\hline family & $0.39 \%$ & $0.91 \%$ & $0.39 \%$ & $0.00 \%$ & $1.43 \%$ & $1.43 \%$ & $4.30 \%$ & $0.39 \%$ & $19.69 \%$ & $3.26 \%$ & $3.00 \%$ & $0.13 \%$ & $0.00 \%$ & $1.43 \%$ & $2.63 \%$ \\
\hline genus & $1.56 \%$ & $1.17 \%$ & $0.52 \%$ & $0.65 \%$ & $1.83 \%$ & $4.95 \%$ & $4.43 \%$ & $3.26 \%$ & $20.21 \%$ & $66.49 \%$ & $3.39 \%$ & $23.47 \%$ & $0.39 \%$ & $1.96 \%$ & $9.59 \%$ \\
\hline
\end{tabular}
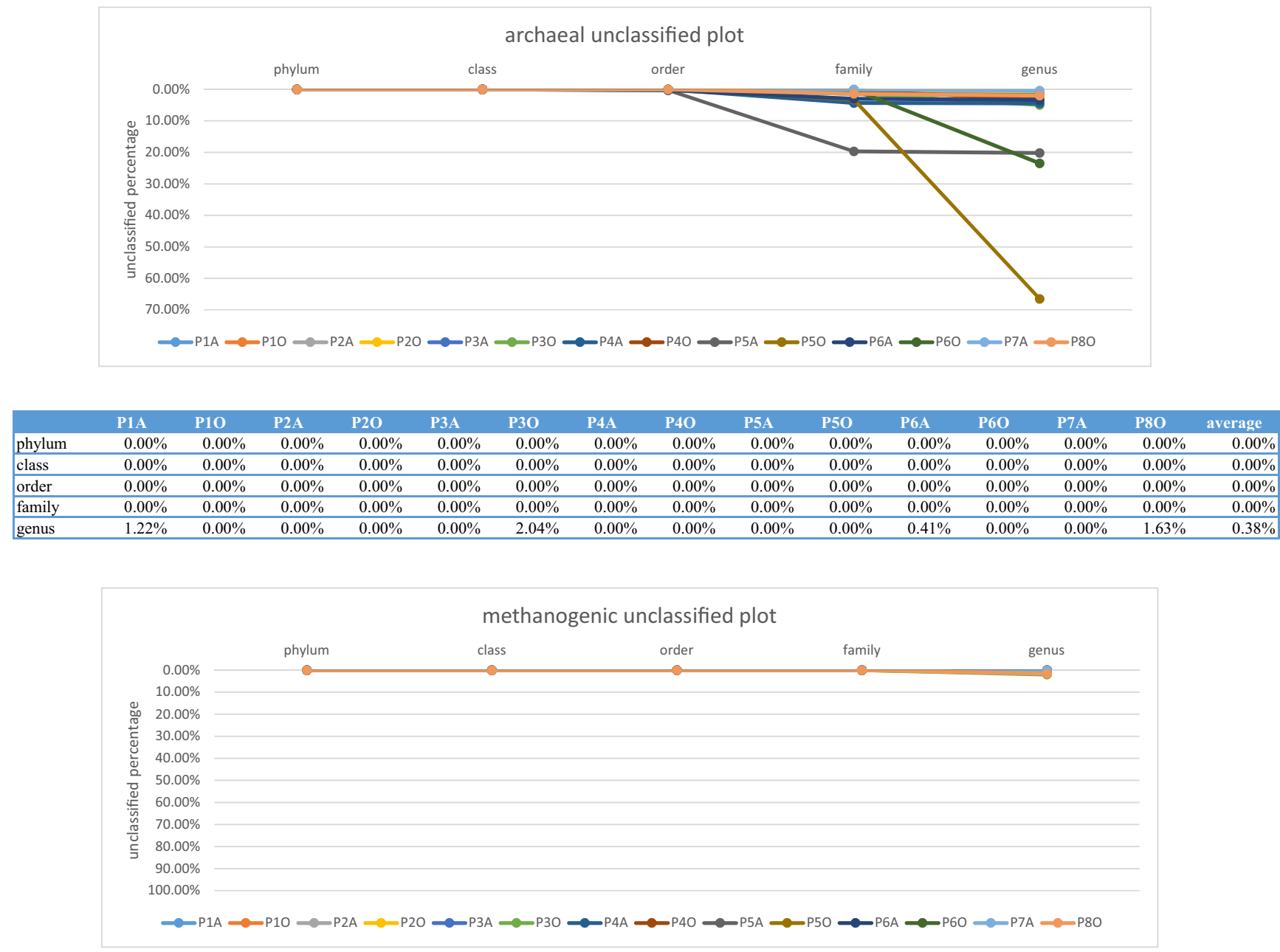
Table S3. Taxonomic composition of aqueous and oil phase samples based on MiSeq 16S rRNA gene sequencing. a) bacterial community composition in genus level; b) archaeal community composition in genus level.

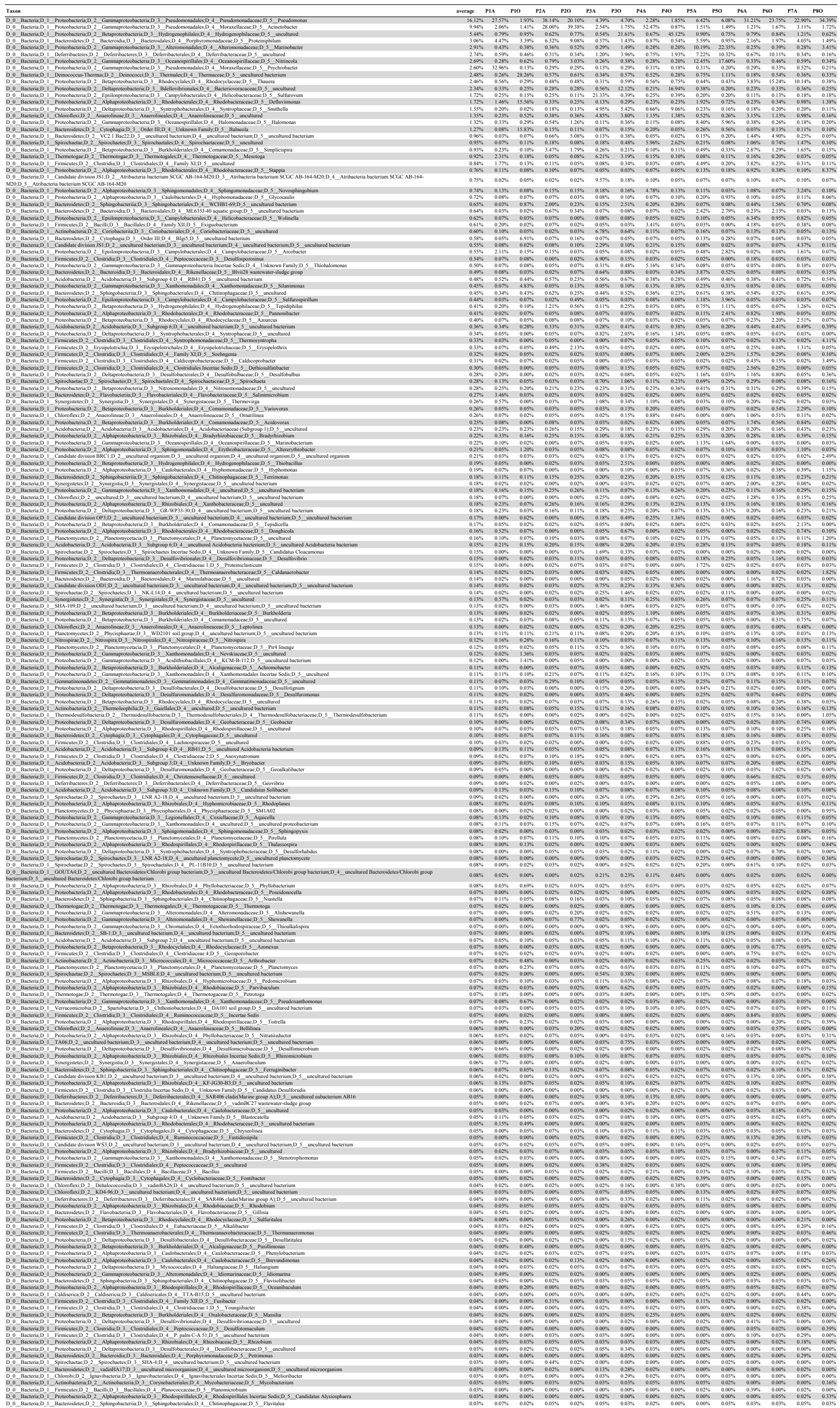




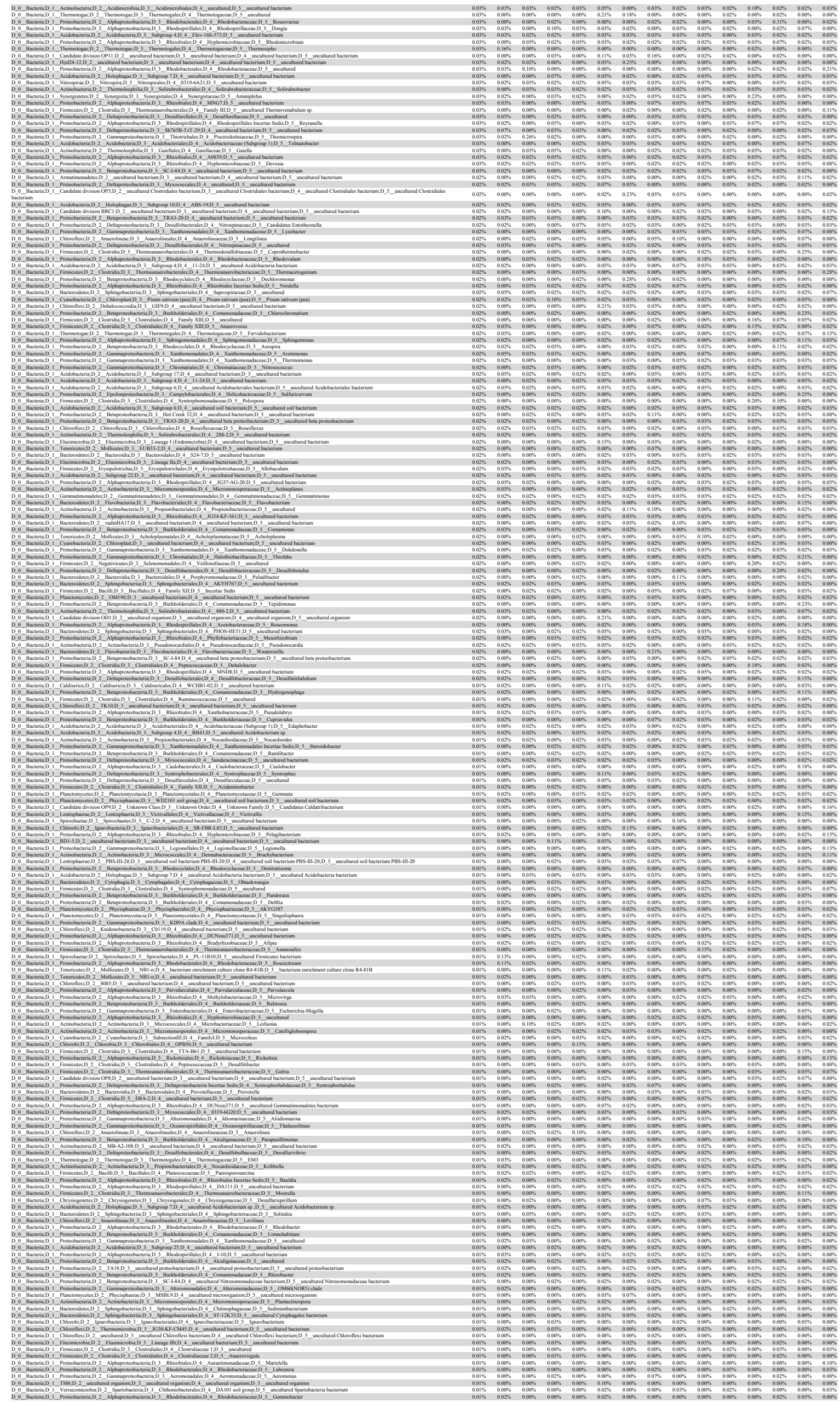




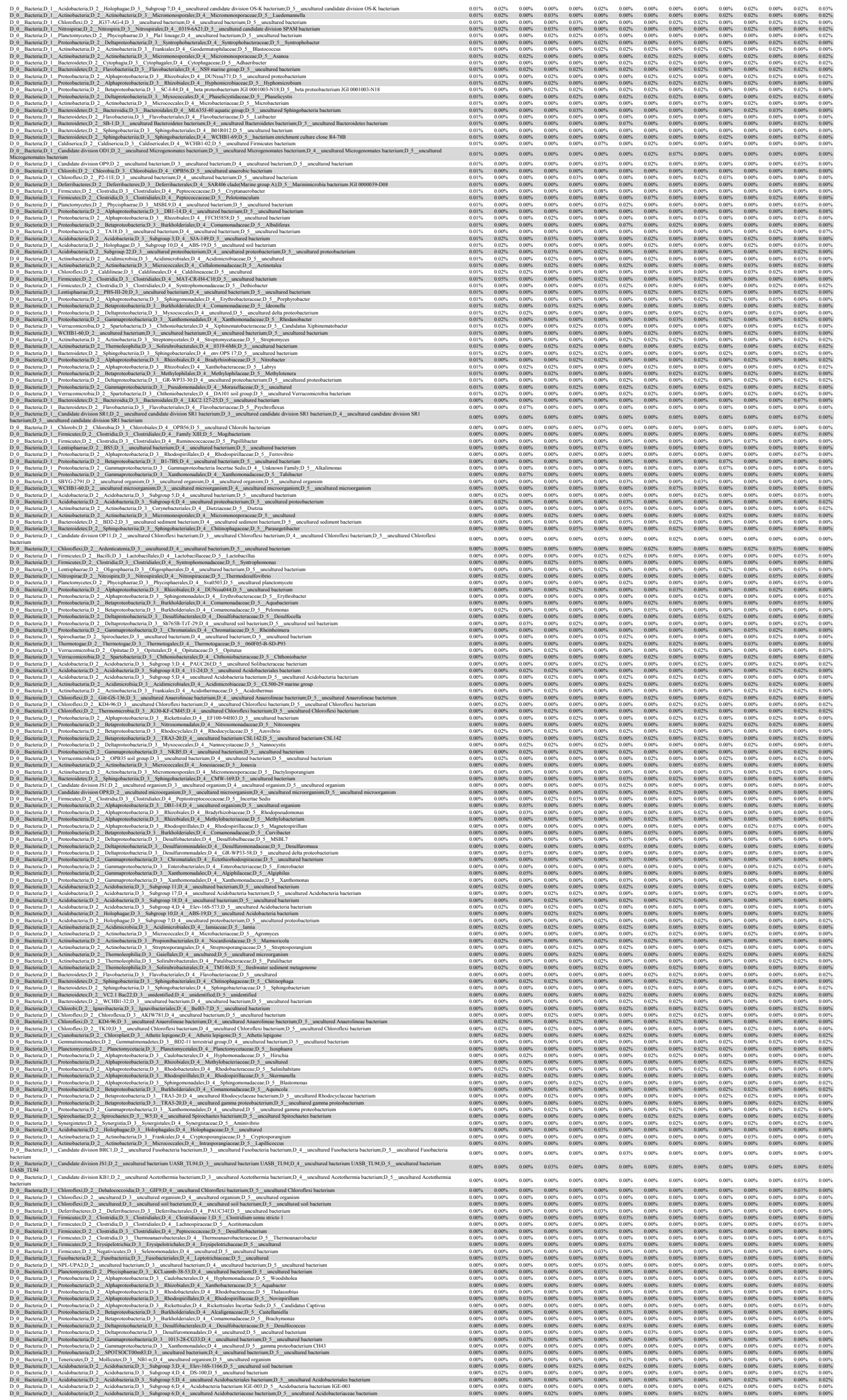




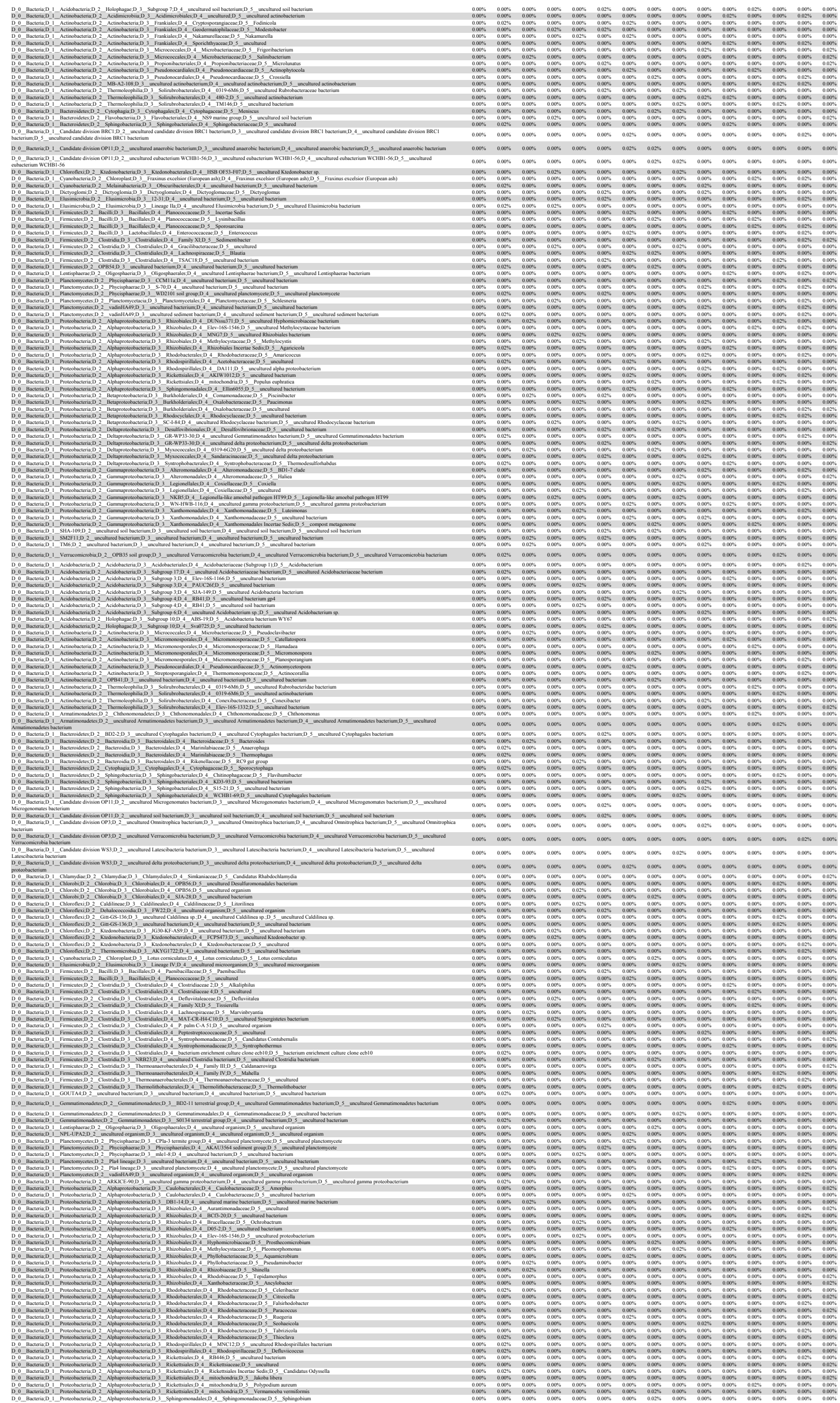




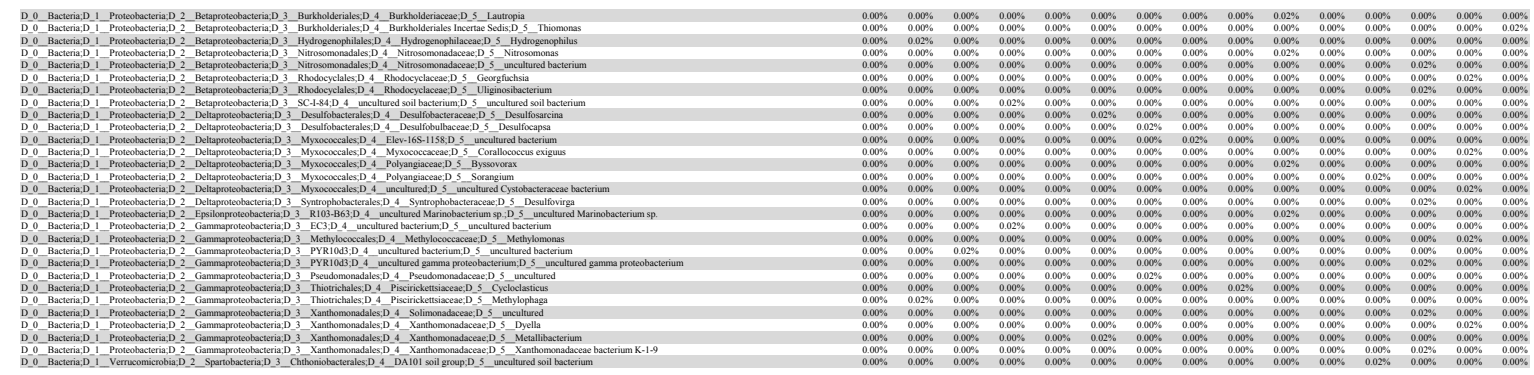




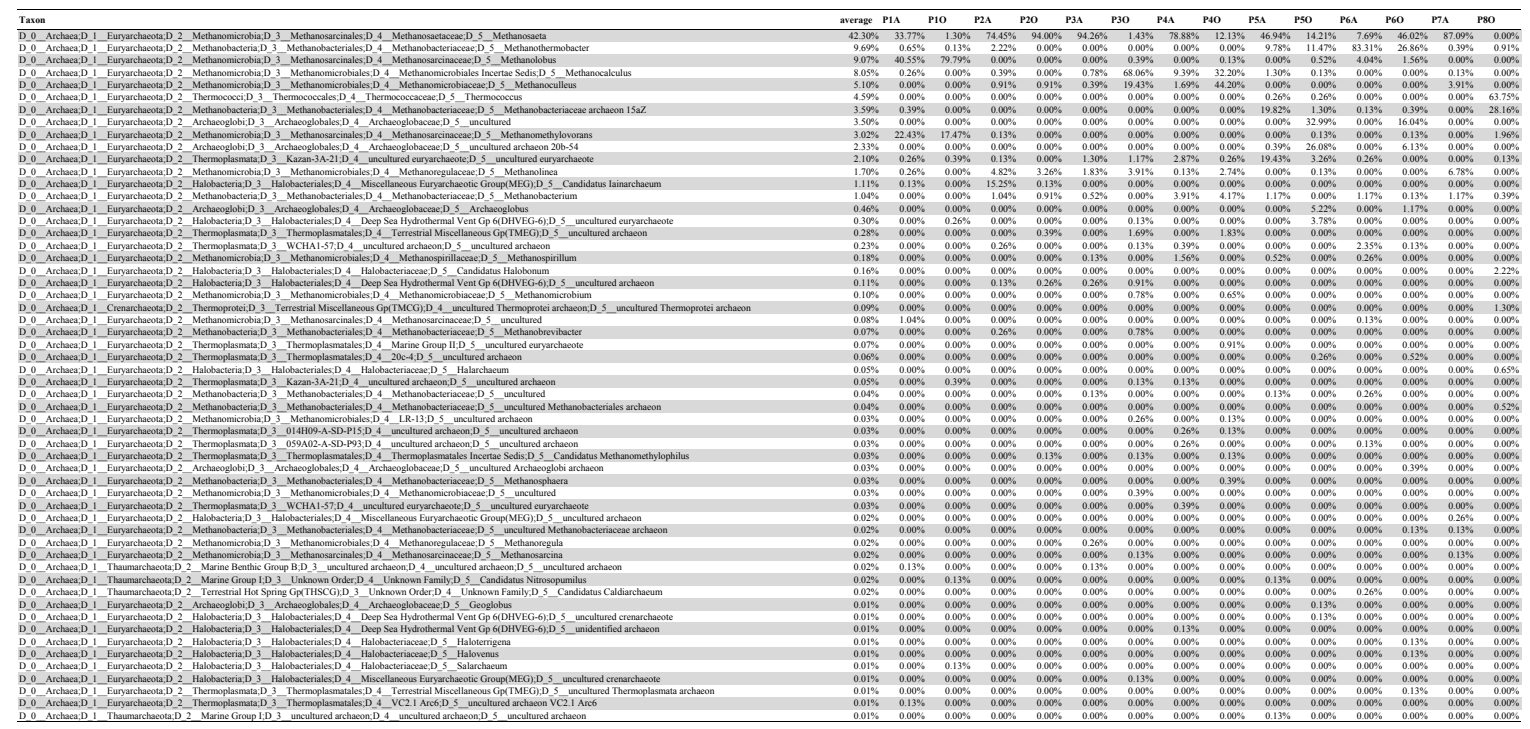


Table S4. Shared OTU numbers of all pairs of samples (I). The statistical table of average shared OTU numbers and the percentages of shared OTU numbers in each sample's OTU numbers (II). a) bacterial community tables; b) archaeal community tables.

a $\mathrm{I}$

\begin{tabular}{|c|c|c|c|c|c|c|c|c|c|c|c|c|c|c|}
\hline & P1A & P10 & P2A & P2O & P3A & P30 & P4A & P40 & P5A & P5O & P6A & P60 & P7A & P80 \\
\hline P1A & 743 & 205 & 228 & 228 & 241 & 248 & 230 & 208 & 265 & 206 & 243 & 249 & 295 & 232 \\
\hline $\mathrm{P} 10$ & 205 & 553 & 195 & 184 & 183 & 207 & 201 & 168 & 235 & 179 & 188 & 218 & 234 & 202 \\
\hline $\mathrm{P} 2 \mathrm{~A}$ & 228 & 195 & 721 & 249 & 235 & 250 & 244 & 202 & 239 & 210 & 247 & 264 & 302 & 225 \\
\hline P2O & 228 & 184 & 249 & 670 & 226 & 237 & 234 & 203 & 254 & 214 & 239 & 237 & 278 & 216 \\
\hline P3A & 241 & 183 & 235 & 226 & 922 & 323 & 296 & 228 & 272 & 217 & 238 & 266 & 306 & 230 \\
\hline P3O & 248 & 207 & 250 & 237 & 323 & 973 & 286 & 338 & 307 & 238 & 269 & 282 & 325 & 240 \\
\hline $\mathrm{P} 4 \mathrm{~A}$ & 230 & 201 & 244 & 234 & 296 & 286 & 795 & 260 & 260 & 204 & 253 & 258 & 300 & 236 \\
\hline $\mathrm{P} 4 \mathrm{O}$ & 208 & 168 & 202 & 203 & 228 & 338 & 260 & 844 & 227 & 176 & 220 & 231 & 259 & 194 \\
\hline P5A & 265 & 235 & 239 & 254 & 272 & 307 & 260 & 227 & 892 & 280 & 273 & 297 & 322 & 269 \\
\hline P5O & 206 & 179 & 210 & 214 & 217 & 238 & 204 & 176 & 280 & 670 & 213 & 245 & 249 & 220 \\
\hline P6A & 243 & 188 & 247 & 239 & 238 & 269 & 253 & 220 & 273 & 213 & 770 & 302 & 329 & 257 \\
\hline $\mathrm{P} 6 \mathrm{O}$ & 249 & 218 & 264 & 237 & 266 & 282 & 258 & 231 & 297 & 245 & 302 & 827 & 330 & 259 \\
\hline P7A & 295 & 234 & 302 & 278 & 306 & 325 & 300 & 259 & 322 & 249 & 329 & 330 & 1033 & 272 \\
\hline P8O & 232 & 202 & 225 & 216 & 230 & 240 & 236 & 194 & 269 & 220 & 257 & 259 & 272 & 727 \\
\hline
\end{tabular}

II $\quad \begin{array}{llllllllllllllll} & \text { P1A } & \text { P10 } & \text { P2A } & \text { P20 } & \text { P3A } & \text { P30 } & \text { P4A } & \text { P40 } & \text { P5A } & \text { P50 } & \text { P6A } & \text { P60 } & \text { P7A } & \text { P80 }\end{array}$

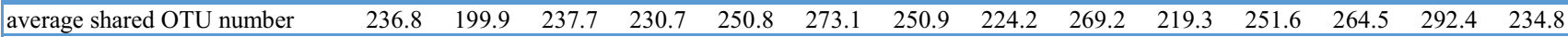

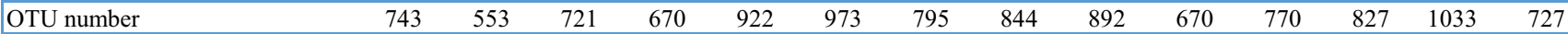

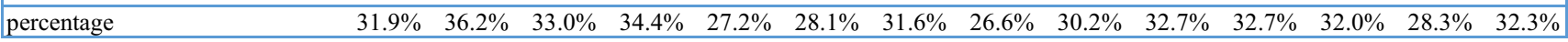

b

\begin{tabular}{|c|c|c|c|c|c|c|c|c|c|c|c|c|c|c|}
\hline & P1A & P10 & P2A & P2O & P3A & P30 & P4A & P40 & P5A & P50 & P6A & P60 & P7A & P80 \\
\hline P1A & 66 & 14 & 17 & 7 & 16 & 7 & 9 & 8 & 18 & 7 & 14 & 7 & 8 & 4 \\
\hline $\mathrm{P} 10$ & 14 & 26 & 4 & 1 & 1 & 2 & 1 & 3 & 3 & 6 & 4 & 5 & 2 & 2 \\
\hline $\mathrm{P} 2 \mathrm{~A}$ & 17 & 4 & 51 & 21 & 25 & 8 & 15 & 12 & 18 & 5 & 12 & 4 & 12 & 2 \\
\hline $\mathrm{P} 2 \mathrm{O}$ & 7 & 1 & 21 & 52 & 12 & 3 & 9 & 6 & 8 & 2 & 5 & 2 & 10 & 0 \\
\hline P3A & 16 & 1 & 25 & 12 & 76 & 10 & 25 & 9 & 21 & 1 & 10 & 1 & 6 & 0 \\
\hline P3O & 7 & 2 & 8 & 3 & 10 & 57 & 11 & 20 & 7 & 2 & 4 & 1 & 2 & 0 \\
\hline P4A & 9 & 1 & 15 & 9 & 25 & 11 & 68 & 18 & 17 & 2 & 10 & 1 & 6 & 0 \\
\hline $\mathrm{P} 4 \mathrm{O}$ & 8 & 3 & 12 & 6 & 9 & 20 & 18 & 72 & 10 & 4 & 5 & 1 & 6 & 0 \\
\hline P5A & 18 & 3 & 18 & 8 & 21 & 7 & 17 & 10 & 55 & 9 & 15 & 5 & 10 & 4 \\
\hline $\mathrm{P} 5 \mathrm{O}$ & 7 & 6 & 5 & 2 & 1 & 2 & 2 & 4 & 9 & 63 & 5 & 19 & 3 & 5 \\
\hline P6A & 14 & 4 & 12 & 5 & 10 & 4 & 10 & 5 & 15 & 5 & 37 & 6 & 7 & 2 \\
\hline $\mathrm{P} 6 \mathrm{O}$ & 7 & 5 & 4 & 2 & 1 & 1 & 1 & 1 & 5 & 19 & 6 & 52 & 8 & 3 \\
\hline P7A & 8 & 2 & 12 & 10 & 6 & 2 & 6 & 6 & 10 & 3 & 7 & 8 & 44 & 1 \\
\hline P8O & 4 & 2 & 2 & 0 & 0 & 0 & 0 & 0 & 4 & 5 & 2 & 3 & 1 & 16 \\
\hline
\end{tabular}

II

\begin{tabular}{|lrrrrrrrrrrrrrr} 
& P1A & P10 & P2A & P2O & P3A & P30 & P4A & P40 & P5A & P50 & P6A & P60 & P7A & P80 \\
average shared OTU number & 10.5 & 3.7 & 11.9 & 6.6 & 10.5 & 5.9 & 9.5 & 7.8 & 11.2 & 5.4 & 7.6 & 4.8 & 6.2 & 1.8 \\
\hline OTU number & 66 & 26 & 51 & 52 & 76 & 57 & 68 & 72 & 55 & 63 & 37 & 52 & 44 & 16 \\
\hline percentage & $15.9 \%$ & $14.2 \%$ & $23.4 \%$ & $12.7 \%$ & $13.9 \%$ & $10.4 \%$ & $14.0 \%$ & $10.9 \%$ & $20.3 \%$ & $8.5 \%$ & $20.6 \%$ & $9.3 \%$ & $14.2 \%$ & $11.1 \%$ \\
\hline
\end{tabular}


Table S5. Functional roles and corresponding reference of core bacterial microbiome in all petroleum samples. Core microbial OTUs (23 OTUs) were affiliated to the most abundant genera.

\begin{tabular}{|c|c|c|c|c|c|}
\hline Genus name & $\begin{array}{l}\text { Average } \\
\text { Abundance }\end{array}$ & Function role & & & References \\
\hline Pseudomonas (Gamma.) & $14.3 \%$ & Hydrocarbon degrader & Nitrate/Nitrite reducer & & $\begin{array}{l}\text { (Ma et al., 2006; Wentzel et al., 2007; Mehboob et al., } \\
\text { 2009; Zhang et al., 2011) }\end{array}$ \\
\hline Acinetobacter (Gamma.) & $7.4 \%$ & Aerobic hydrocarbon degrader & & & $\begin{array}{l}\text { (Lal and Khanna, 1996; DiCello et al., 1997; Zhang et } \\
\text { al., 2014) }\end{array}$ \\
\hline Hydrogenophilaceae UG (Beta.) & $5.0 \%$ & Fermentative bacteria & Nitrate/Nitrite reducer & & (Hayashi et al., 1999; Salinas et al., 2004) \\
\hline Marinobacter (Gamma.) & $2.8 \%$ & Hydrocarbon degrader & Nitrate/Nitrite reducer & & (Gauthier et al., 1992; Takai et al., 2005) \\
\hline Nitrincola (Gamma.) & $2.6 \%$ & Aerobic hydrocarbon degrader & Nitrate/Nitrite reducer & & (Dimitriu et al., 2005; Tiquia, 2010) \\
\hline Thermaceae UG (D.-T.) & $2.4 \%$ & Fermentative bacteria & Nitrate/Nitrite reducer & & $\begin{array}{l}\text { (Miroshnichenko et al., 2003a; Miroshnichenko et al., } \\
\text { 2003b) }\end{array}$ \\
\hline Proteiniphilum (Bac.) & $2.4 \%$ & Hydrocarbon degrader & & & (Chen and Dong, 2005; Gargouri et al., 2014) \\
\hline Deferribacteraceae UG (Deferri.) & $2.2 \%$ & Hydrocarbon degrader & Nitrate/Nitrite reducer & Sulfidogenic bacteria (SRB) & (Greene et al., 1997; Takai et al., 2003) \\
\hline Thauera (Beta.) & $2.1 \%$ & Hydrocarbon degrader & Nitrate/Nitrite reducer & & $\begin{array}{l}\text { (Foss and Harder, 1998; Song et al., 2001; Mechichi et } \\
\text { al., 2002; Dubbels et al., 2009; Sun and Cupples, 2012) }\end{array}$ \\
\hline Bacteriovoracaceae UG (Delta.) & $2.1 \%$ & & & & \\
\hline Psychrobacter (Gamma.) & $1.9 \%$ & Aerobic hydrocarbon degrader & & & (Deppe et al., 2005; Bowman and Deming, 2014) \\
\hline Sulfurovum (Epsilon.) & $1.7 \%$ & Sulfur cycling bacteria & & & (Inagaki et al., 2004; Mino et al., 2014) \\
\hline Defluviimonas (Alpha.) & $1.3 \%$ & Nitrate/Nitrite reducer & & & (Foesel et al., 2011; Pan et al., 2015) \\
\hline Balneola (Bac.) & $1.2 \%$ & Aerobic hydrocarbon degrader & & & (Urios et al., 2006; Urios et al., 2008; Li et al., 2012) \\
\hline Mesotoga (Thermo.) & $0.9 \%$ & Hydrocarbon degrader & Fermentative bacteria & Sulfidogenic bacteria (SRB) & $\begin{array}{l}\text { (Nesbo et al., 2012; Ben Hania et al., 2013) (Rosenberg } \\
\text { et al., 2014) }\end{array}$ \\
\hline VC2.1 Bac22 UG (Bac.) & $0.8 \%$ & & & & \\
\hline Simplicispira (Beta.) & $0.8 \%$ & & & & \\
\hline Stappia (Alpha.) & $0.7 \%$ & Aerobic hydrocarbon degrader & & & (Al-Awadhi et al., 2007; Lai et al., 2010) \\
\hline Glycocaulis (Alpha.) & $0.7 \%$ & Aerobic hydrocarbon degrader & & & (Lv et al., 2014; Geng et al., 2015) \\
\hline ML635J-40 aquatic group UG (Bac.) & $0.6 \%$ & Fermentative bacteria & & & (Nolla-Ardevol et al., 2015) \\
\hline Spirochaetaceae UG (Spiro.) & $0.6 \%$ & Fermentative bacteria & Acetogen & & (Graber and Breznak, 2004; Cheng et al., 2013) \\
\hline Novosphingobium (Alpha.) & $0.6 \%$ & Hydrocarbon degrader & Nitrate/Nitrite reducer & & $\begin{array}{l}\text { (Sohn et al., 2004; Liu et al., 2005; Addison et al., 2007; } \\
\text { Niharika et al., 2013) }\end{array}$ \\
\hline Clostridiales Family XI UG (Fir.) & $0.5 \%$ & Fermentative bacteria & Sulfidogenic bacteria (SRB) & Syntrophic acetate oxidizer & (Jones and Vandecasteele, 2008; Müller et al., 2013) \\
\hline Others & $44.4 \%$ & & & & \\
\hline
\end{tabular}


Table S6. The taxonomic summary of shared OTUs of bacterial communities between a) aqueous samples, b) oil samples, c) all samples. Red labeled genera acquired average proportional size over $0.5 \%$.

a

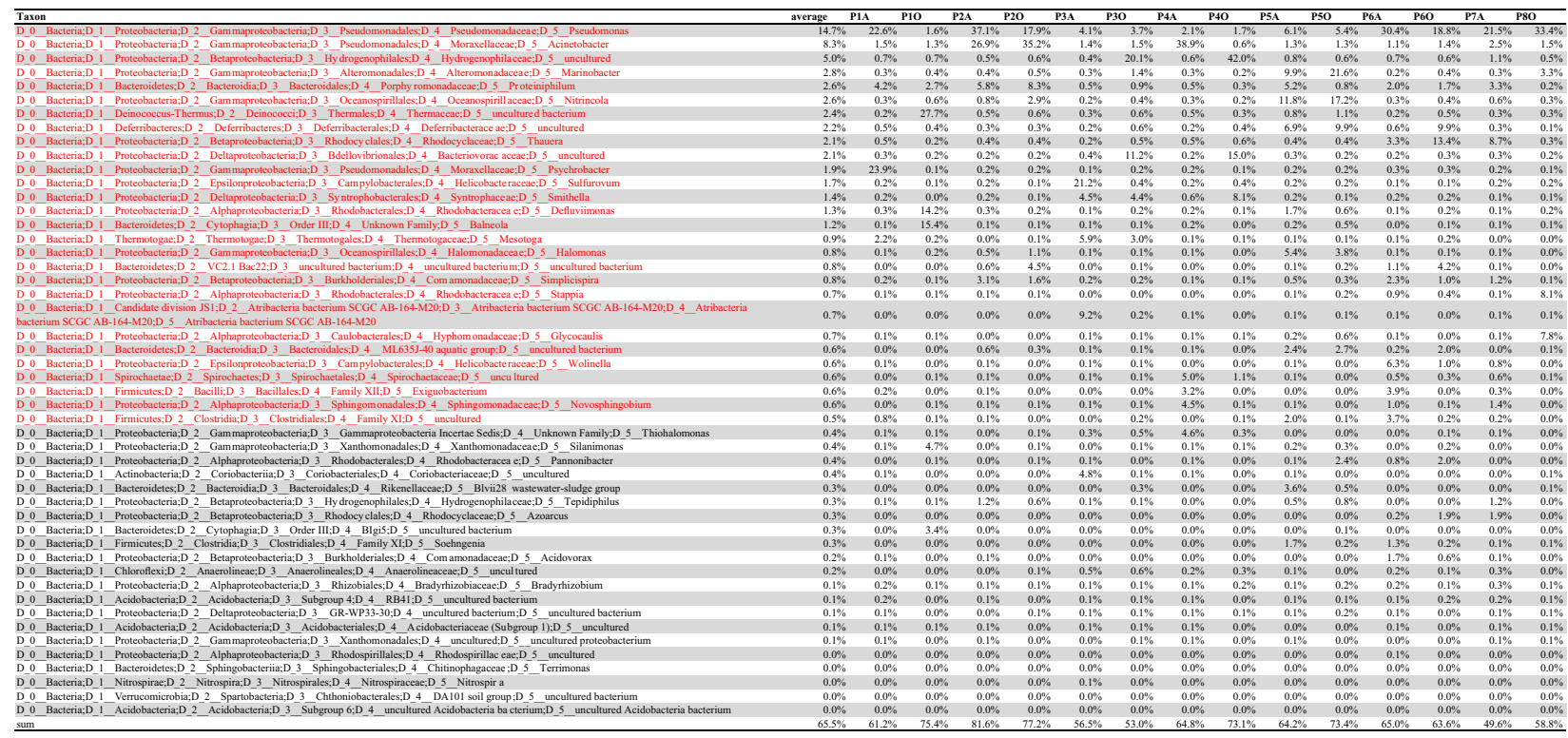

b

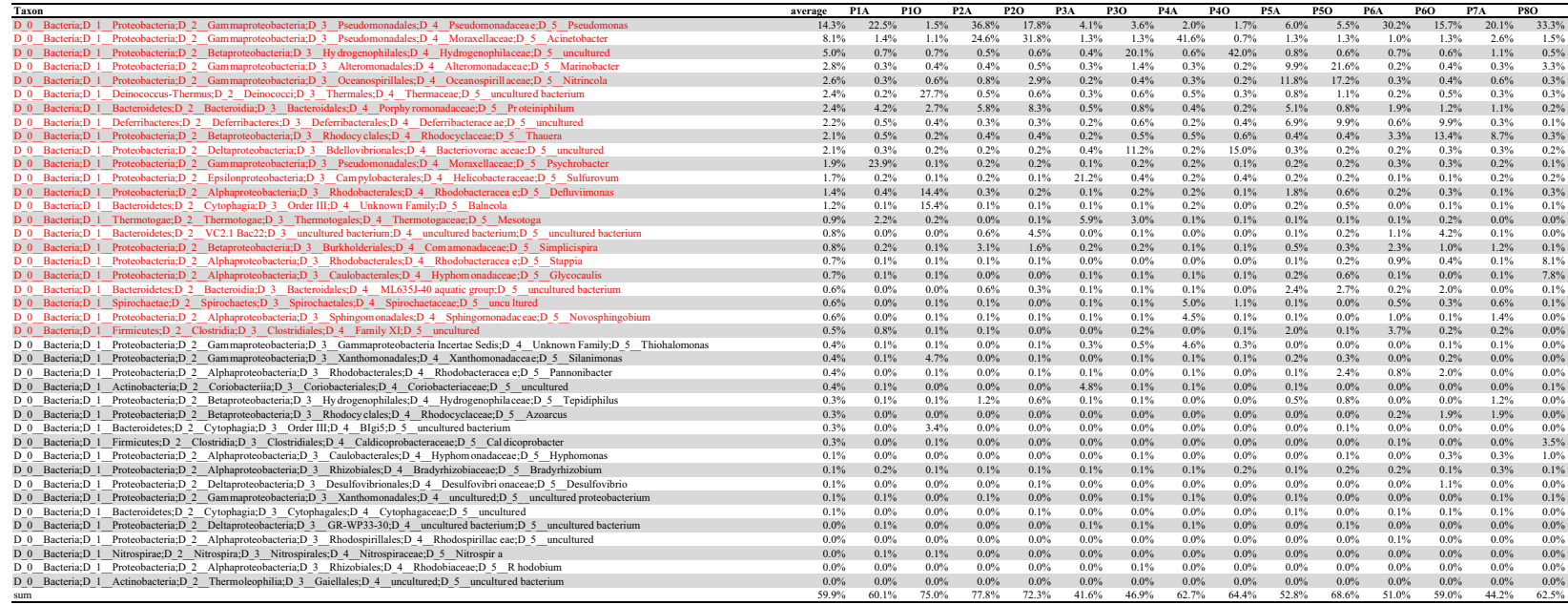

C

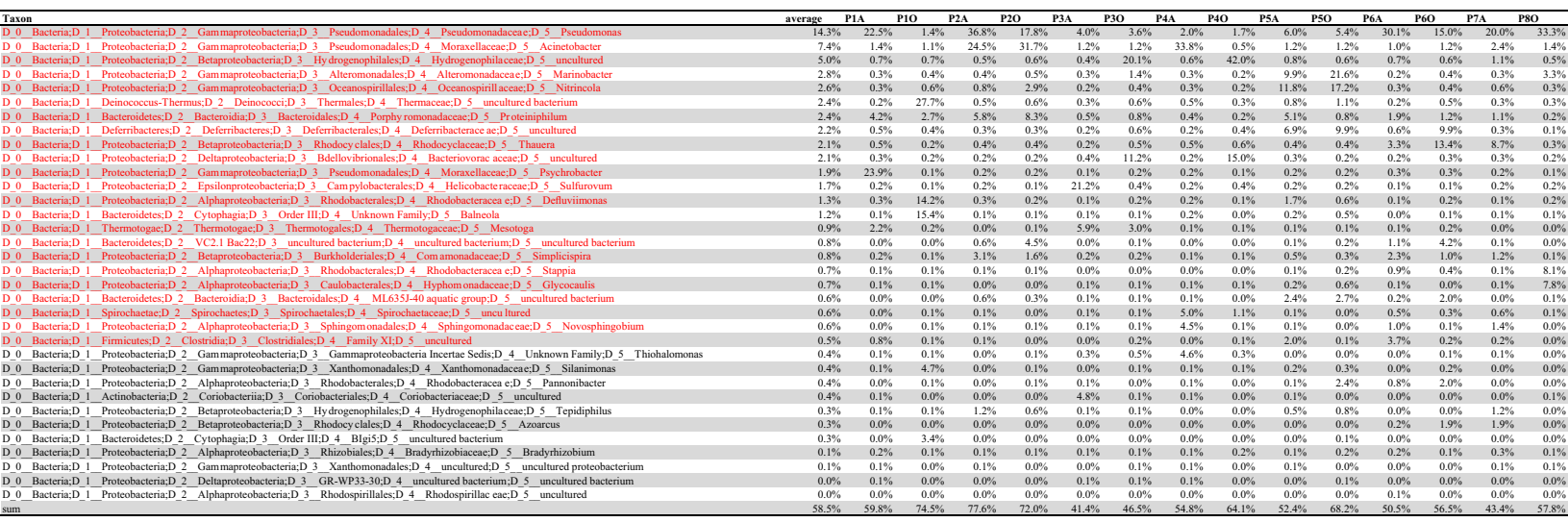


Table S7. Statistical significance test based on unweighted UniFrac distance matrix which obtained from beta diversity analysis

\begin{tabular}{lllllll} 
& & \multicolumn{2}{c}{ anosim } & & \multicolumn{2}{c}{ adonis } \\
\cline { 3 - 4 } \cline { 5 - 6 } \cline { 5 - 6 } bacteria & Group & $0.5137^{* *}$ & $0.007^{* *}$ & & $0.5773^{* *}$ & $0.003^{* *}$ \\
& $\mathrm{pH}$ & 0.1531 & 0.070 & & $0.0949^{*}$ & $0.016^{*}$ \\
& Phase & -0.0049 & 0.493 & & 0.0741 & 0.625 \\
& Temperature & $0.5257^{* *}$ & $0.002^{* *}$ & & $0.2001^{* *}$ & $0.001^{* *}$ \\
archaea & Group & 0.3255 & 0.050 & & $0.5963^{*}$ & $0.024^{*}$ \\
& pH & $0.2297^{*}$ & $0.029^{*}$ & & $0.1107^{*}$ & $0.034^{*}$ \\
& Phase & $0.2284^{*}$ & $0.020^{*}$ & & $0.1142^{*}$ & $0.022^{*}$ \\
& Temperature & 0.1967 & 0.101 & & $0.1948^{*}$ & $0.038^{*}$ \\
& Group & $0.3176^{*}$ & $0.031^{*}$ & & $0.6302^{*}$ & $0.017^{*}$ \\
& pH & 0.0378 & 0.280 & & 0.1054 & 0.090 \\
& Phase & 0.0894 & 0.115 & & 0.0964 & 0.147 \\
& Temperature & $0.3421^{*}$ & $0.016^{*}$ & & $0.2430^{* *}$ & $0.003^{* *}$ \\
\hline
\end{tabular}

Scores with $p$-value less than 0.05 were labeled with one star, scores with $p$-value less than 0.01 were labeled with two stars. 
Table S8. Mantel test based on the beta diversity results by unweighted \& weighted UniFrac matrix and Bray-Curtis (non-phylogenetic) matrix measurement. The aqueous and oil phase samples were analyzed separately. The physiochemical parameter distance matrices were also separately used according to phase difference. The significant scores $(p$-value $<0.05)$ were highlighted.
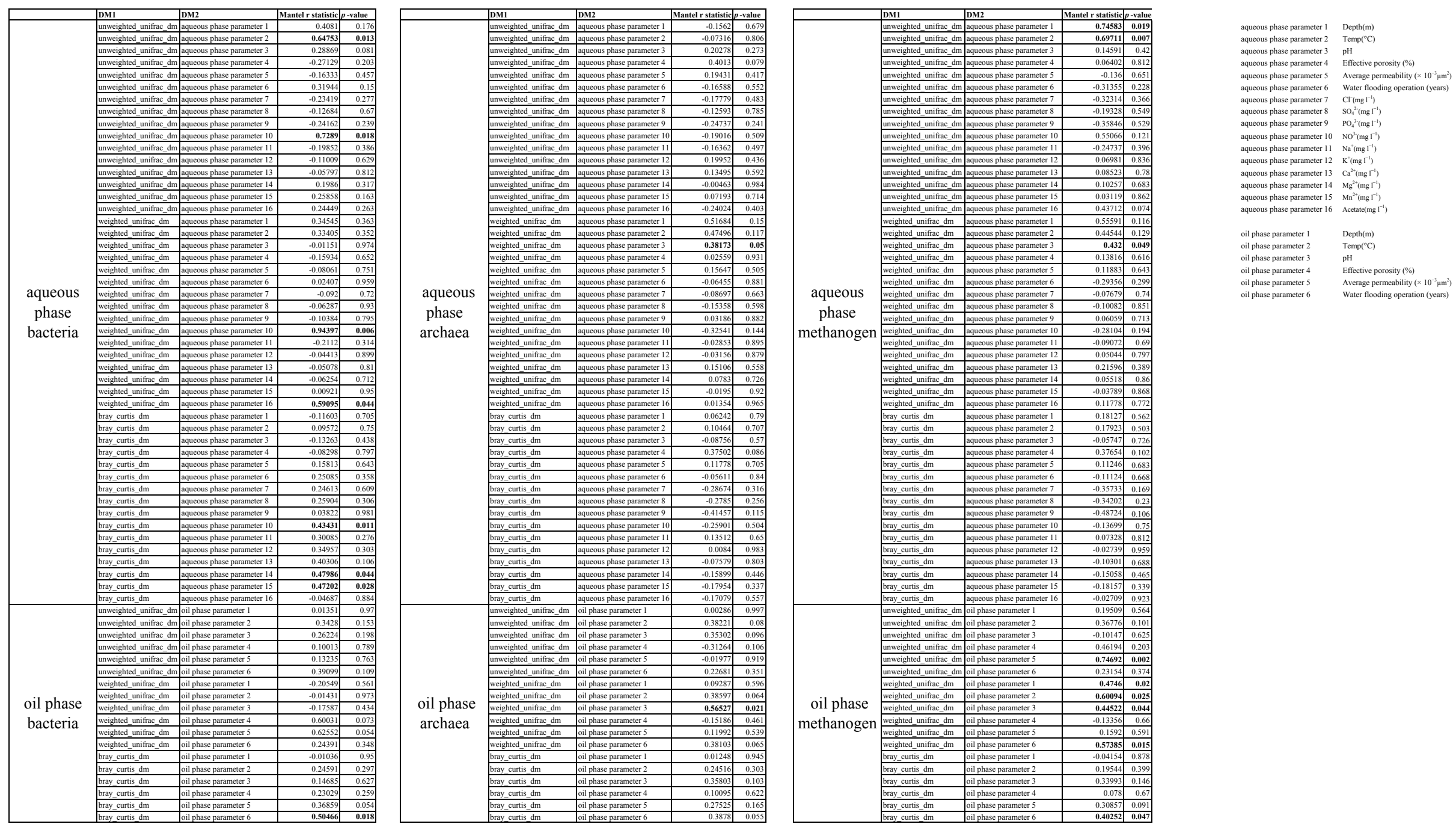
Table S9. Predicted functional profiles based on microbial $16 \mathrm{~S}$ taxonomic abundance dataset. a) bacterial community functional profiles; b) archaeal community functional profiles. FTU:Fraction of OTUs that could not be mapped to KEGG organisms.

a

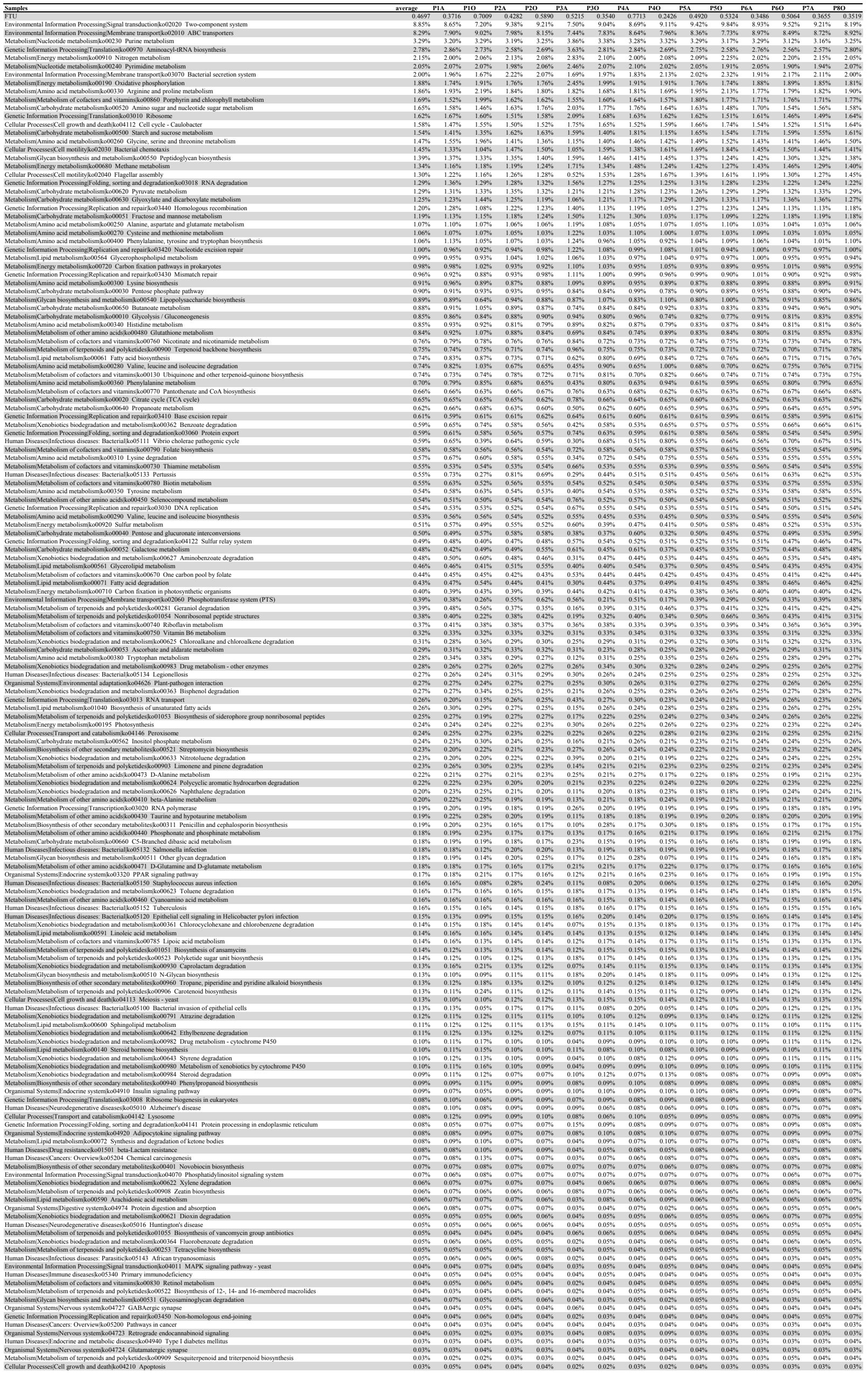




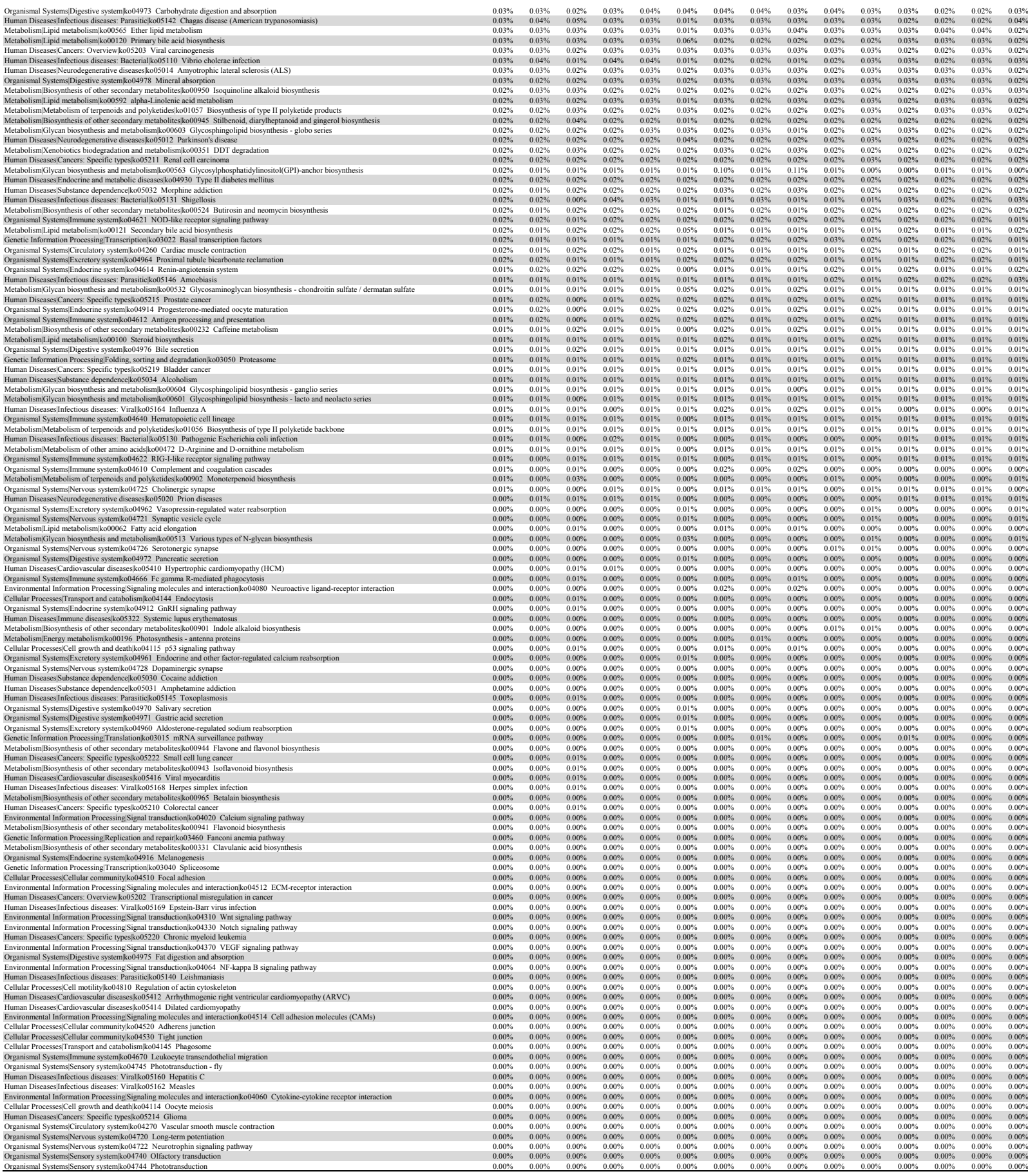
b

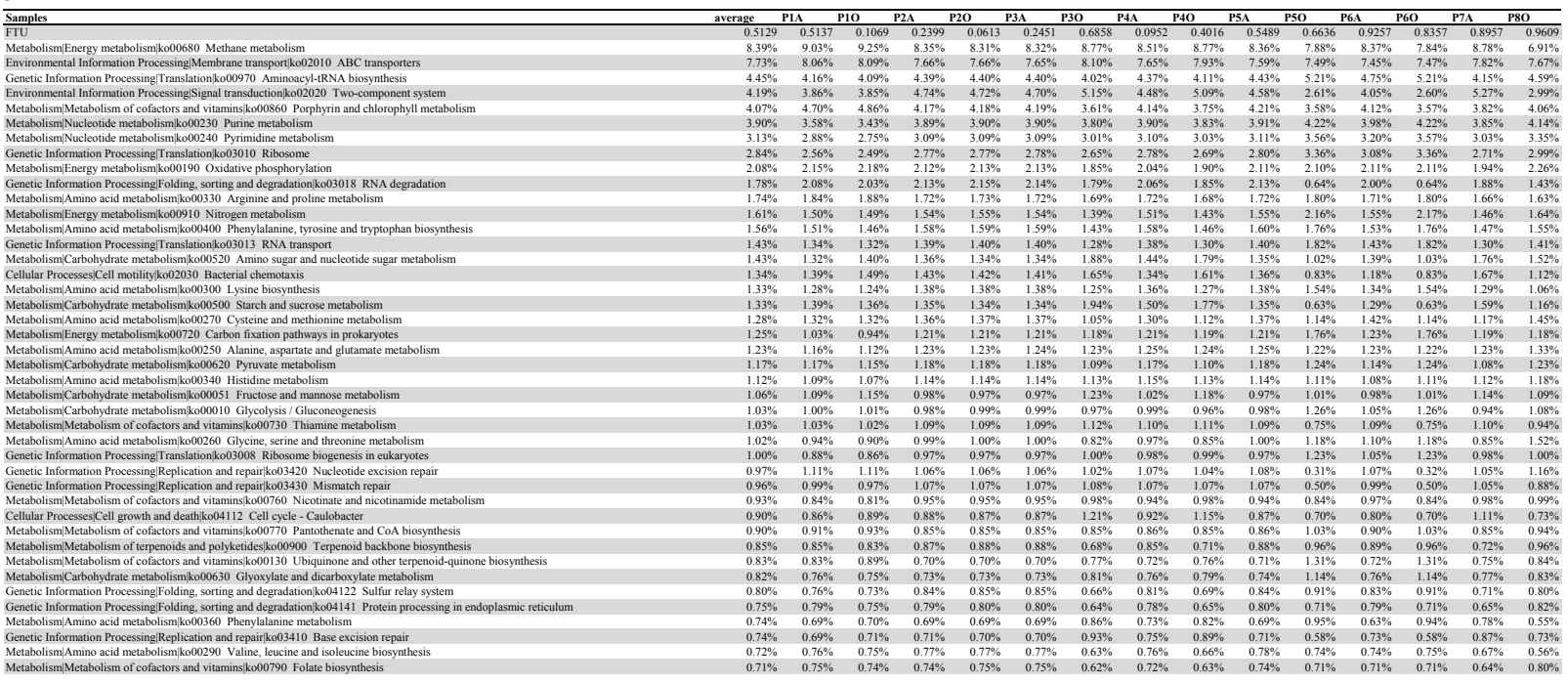




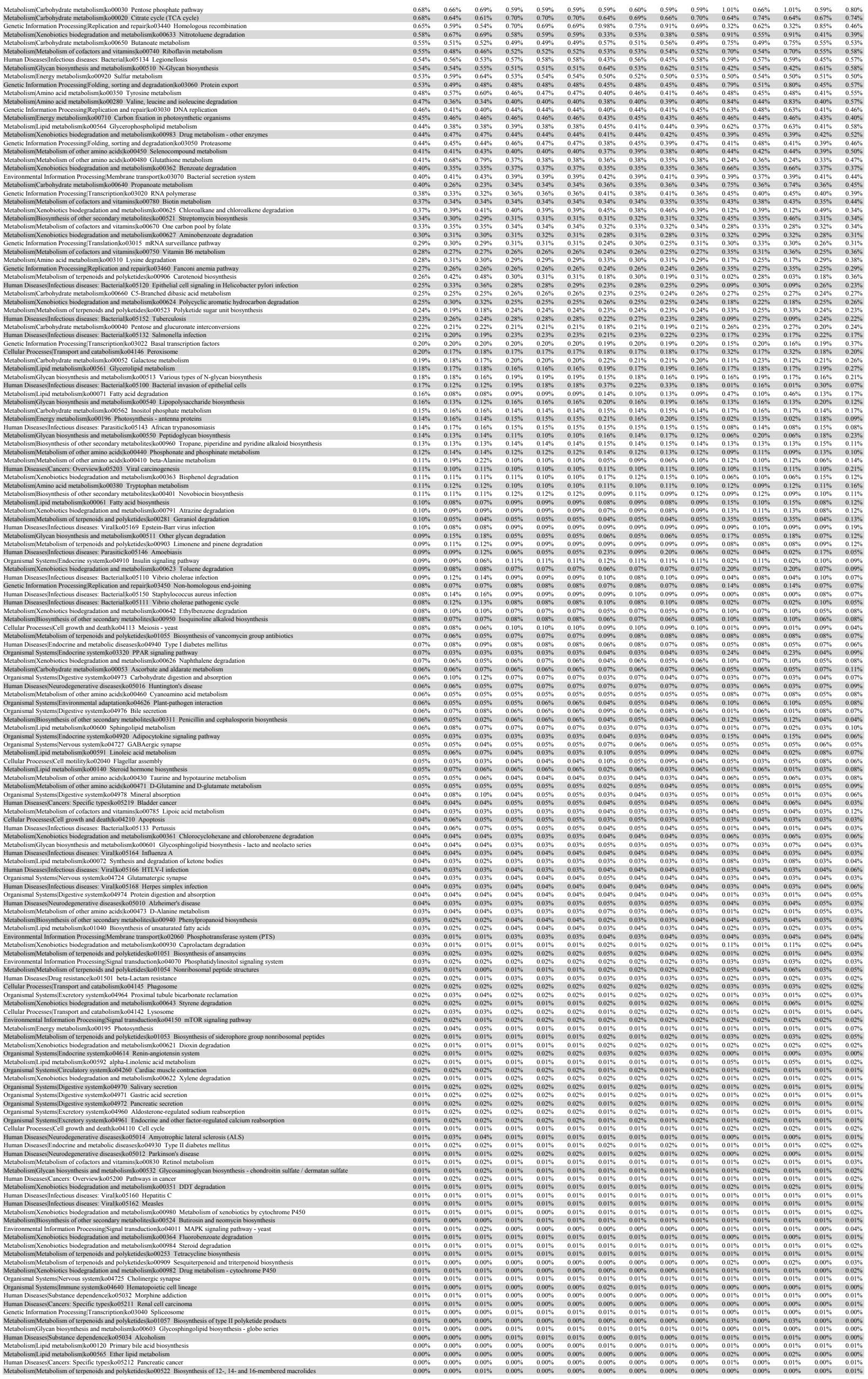




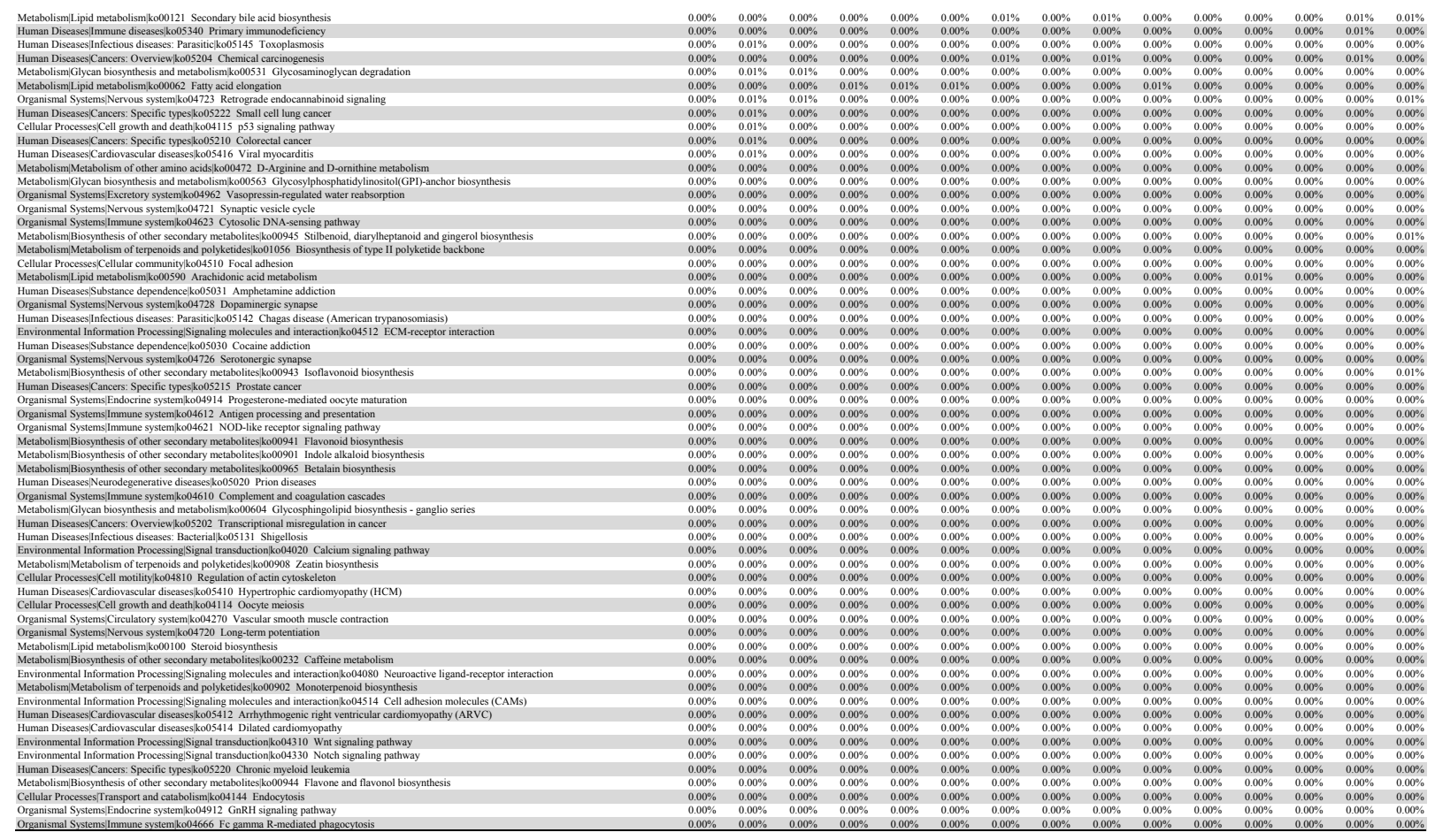




\section{References:}

Addison, S.L., Foote, S.M., Reid, N.M., and Lloyd-Jones, G. (2007). Novosphingobium nitrogenifigens sp. nov., a polyhydroxyalkanoate-accumulating diazotroph isolated from a New Zealand pulp and paper wastewater. Int. J. Syst. Evol. Microbiol. 57, 2467-2471. doi: doi:10.1099/ijs.0.64627-0.

Al-Awadhi, H., Sulaiman, R.H.D., Mahmoud, H.M., and Radwan, S.S. (2007). Alkaliphilic and halophilic hydrocarbon-utilizing bacteria from Kuwaiti coasts of the Arabian Gulf. Appl. Microbiol. Biotechnol. 77, 183-186. doi: 10.1007/s00253-007-1127-1.

Ben Hania, W., Postec, A., Auello, T., Ranchou-Peyruse, A., Erauso, G., Brochier-Armanet, C., Hamdi, M., Ollivier, B., Saint-Laurent, S., Magot, M., and Fardeau, M.-L. (2013). Mesotoga infera sp nov., a mesophilic member of the order Thermotogales, isolated from an underground gas storage aquifer. Int. J. Syst. Evol. Microbiol. 63, 3003-3008. doi: 10.1099/ijs.0.047993-0.

Bowman, J.S., and Deming, J.W. (2014). Alkane hydroxylase genes in psychrophile genomes and the potential for cold active catalysis. BMC Genomics 15. doi: 10.1186/14712164-15-1120.

Chen, S.Y., and Dong, X.Z. (2005). Proteiniphilum acetatigenes gen. nov., sp nov., from a UASB reactor treating brewery wastewater. Int. J. Syst. Evol. Microbiol. 55, 22572261. doi: 10.1099/ijs.0.63807-0.

Cheng, L., Ding, C., Li, Q., He, Q., Dai, L.-R., and Zhang, H. (2013). DNA-SIP Reveals That Syntrophaceae Play an Important Role in Methanogenic Hexadecane Degradation. PLoS One 8. doi: 10.1371/journal.pone.0066784.

Deppe, U., Richnow, H.H., Michaelis, W., and Antranikian, G. (2005). Degradation of crude oil by an arctic microbial consortium. Extremophiles 9, 461-470. doi: 10.1007/s00792-005-0463-2.

Dicello, F., Pepi, M., Baldi, F., and Fani, R. (1997). Molecular characterization of an $n$-alkane-degrading bacterial community and identification of a new species, Acinetobacter venetianus. Res. Microbiol. 148, 237-249. doi: 10.1016/s0923-2508(97)85244-8.

Dimitriu, P.A., Shukla, S.K., Conradt, J., Marquez, M.C., Ventosa, A., Maglia, A., Peyton, B.M., Pinkart, H.C., and Mormile, M.R. (2005). Nitrincola lacisaponensis gen. nov., sp nov., a novel alkaliphilic bacterium isolated from an alkaline, saline lake. Int. J. Syst. Evol. Microbiol. 55, 2273-2278. doi: 10.1099/ijs.0.63647-0.

Dubbels, B.L., Sayavedra-Soto, L.A., Bottomley, P.J., and Arp, D.J. (2009). Thauera butanivorans sp nov., a C-2-C-9 alkane-oxidizing bacterium previously referred to as 'Pseudomonas butanovora'. Int. J. Syst. Evol. Microbiol. 59, 1576-1578. doi: 10.1099/ijs.0.000638-0.

Foesel, B.U., Drake, H.L., and Schramm, A. (2011). Defluviimonas denitrificans gen. nov., sp nov., and Pararhodobacter aggregans gen. nov., sp nov., non-phototrophic Rhodobacteraceae from the biofilter of a marine aquaculture. Syst. Appl. Microbiol. 34, 498-502. doi: 10.1016/j.syapm.2011.08.006.

Foss, S., and Harder, J. (1998). Thauera linaloolentis sp. nov. and Thauera terpenica sp. nov., isolated on oxygen-containing monoterpenes (linalool, menthol, and eucalyptol) and nitrate. Syst. Appl. Microbiol. 21, 365-373. 
Gargouri, B., Karray, F., Mhiri, N., Aloui, F., and Sayadi, S. (2014). Bioremediation of petroleum hydrocarbons-contaminated soil by bacterial consortium isolated from an industrial wastewater treatment plant. J. Chem. Technol. Biotechnol. 89, 978-987. doi: 10.1002/jctb.4188.

Gauthier, M.J., Lafay, B., Christen, R., Fernandez, L., Acquaviva, M., Bonin, P., and Bertrand, J.C. (1992). Marinobacter hydrocarbonoclasticus gen. nov., sp. nov., a new, extremely halotolerant, hydrocarbon-degrading marine bacterium. Int. J. Syst. Bacteriol. 42, 568-576.

Geng, S., Pan, X.-C., Mei, R., Wang, Y.-N., Liu, X.-Y., Wang, X.-B., Tang, Y.-Q., and Wu, X.-L. (2015). Glycocaulis alkaliphilus sp nov., a dimorphic prosthecate bacterium isolated from crude oil. Int. J. Syst. Evol. Microbiol. 65, 838-844. doi: 10.1099/ijs.0.000023.

Graber, J.R., and Breznak, J.A. (2004). Physiology and nutrition of Treponema primitia, an $\mathrm{H}_{2} / \mathrm{CO}_{2}$ acetogenic Spirochete from termite hindguts. Appl. Environ. Microbiol. 70, 1307-1314. doi: 10.1128/aem.70.3.1307-1314.2004.

Greene, A.C., Patel, B.K.C., and Sheehy, A.J. (1997). Deferribacter thermophilus gen nov, sp nov, a novel thermophilic manganese- and iron-reducing bacterium isolated from a petroleum reservoir. Int. J. Syst. Bacteriol. 47, 505-509.

Hayashi, N.R., Ishida, T., Yokota, A., Kodama, T., and Igarashi, Y. (1999). Hydrogenophilus thermoluteolus gen, nov., sp. nov., a thermophilic, facultatively chemolithoautotrophic, hydrogen-oxidizing bacterium. Int. J. Syst. Bacteriol. 49, 783-786.

Inagaki, F., Takai, K., Nealson, K.H., and Horikoshi, K. (2004). Sulfurovum lithotrophicum gen. nov., sp nov., a novel sulfur-oxidizing chemolithoautotroph within the epsilonProteobacteria isolated from Okinawa Trough hydrothermal sediments. Int. J. Syst. Evol. Microbiol. 54, 1477-1482. doi: 10.1099/ijs.0.03042-0.

Jones, T., and Vandecasteele, J.-P. (2008). Petroleum Microbiology. Editions OPHRYS.

Lai, Q., Qiao, N., Wu, C., Sun, F., Yuan, J., and Shao, Z. (2010). Stappia indica sp nov., isolated from deep seawater of the Indian Ocean. Int. J. Syst. Evol. Microbiol. 60, 733736. doi: 10.1099/ijs.0.013417-0.

Lal, B., and Khanna, S. (1996). Degradation of crude oil by Acinetobacter calcoaceticus and Alcaligenes odorans. J. Appl. Bacteriol. 81, 355-362.

Li, H., Zhang, Q., Wang, X.-L., Ma, X.-Y., Lin, K.-F., Liu, Y.-D., Gu, J.-D., Lu, S.-G., Shi, L., Lu, Q., and Shen, T.-T. (2012). Biodegradation of benzene homologues in contaminated sediment of the East China Sea. Bioresour. Technol. 124, 129-136. doi: 10.1016/j.biortech.2012.08.033.

Liu, Z.P., Wang, B.J., Liu, Y.H., and Liu, S.J. (2005). Novosphingobium taihuense sp nov., a novel aromatic-compound-degrading bacterium isolated from Taihu Lake, China. Int. J. Syst. Evol. Microbiol. 55, 1229-1232. doi: 10.1099/ijs.0.63468-0.

Lv, X.-L., Xie, B.-S., Cai, M., Geng, S., Tang, Y.-Q., Wang, Y.-N., Cui, H.-L., Liu, X.-Y., Ye, S.-Y., and Wu, X.-L. (2014). Glycocaulis albus sp nov., a moderately halophilic dimorphic prosthecate bacterium isolated from petroleum-contaminated saline soil. Int. J. Syst. Evol. Microbiol. 64, 3181-3187. doi: 10.1099/ijs.0.063537-0.

Müller, B., Sun, L., and Schnürer, A. (2013). First insights into the syntrophic acetate-oxidizing bacteria - a genetic study. MicrobiologyOpen 2, 35-53. doi: 10.1002/mbo3.50. Ma, Y.F., Wang, L., and Shao, Z.Z. (2006). Pseudomonas, the dominant polycyclic aromatic hydrocarbon-degrading bacteria isolated from Antarctic soils and the role of large 
plasmids in horizontal gene transfer. Environ. Microbiol. 8, 455-465. doi: 10.1111/j.1462-2920.2005.00911.x.

Mechichi, T., Stackebrandt, E., Gad'on, N., and Fuchs, G. (2002). Phylogenetic and metabolic diversity of bacteria degrading aromatic compounds under denitrifying conditions, and description of Thauera phenylacetica sp nov., Thauera aminoaromatica sp nov., and Azoarcus buckelii sp nov. Arch. Microbiol. 178, 26-35. doi: 10.1007/s00203002-0422-6.

Mehboob, F., Junca, H., Schraa, G., and Stams, A.J.M. (2009). Growth of Pseudomonas chloritidismutans AW-1 ${ }^{\mathrm{T}}$ on $n$-alkanes with chlorate as electron acceptor. Appl. Microbiol. Biotechnol. 83, 739-747. doi: 10.1007/s00253-009-1985-9.

Mino, S., Kudo, H., Arai, T., Sawabe, T., Takai, K., and Nakagawa, S. (2014). Sulfurovum aggregans sp nov., a hydrogenoxidizing, thiosulfate-reducing chemolithoautotroph within the Epsilonproteobacteria isolated from a deep-sea hydrothermal vent chimney, and an emended description of the genus Sulfurovum. Int. J. Syst. Evol. Microbiol. 64, 3195-3201. doi: 10.1099/ijs.0.065094-0.

Miroshnichenko, M.L., L'haridon, S., Jeanthon, C., Antipov, A.N., Kostrikina, N.A., Tindall, B.J., Schumann, P., Spring, S., Stackebrandt, E., and Bonch-Osmolovskaya, E.A. (2003a). Oceanithermus profundus gen. nov., sp nov., a thermophilic, microaerophilic, facultatively chemolithoheterotrophic bacterium from a deep-sea hydrothermal vent. Int. J. Syst. Evol. Microbiol. 53, 747-752. doi: 10.1099/ijs.0.02367-0.

Miroshnichenko, M.L., L'haridon, S.L., Nercessian, O., Antipov, A.N., Kostrikina, N.A., Tindall, B.J., Schumann, P., Spring, S., Stackebrandt, E., Bonch-Osmolovskaya, E.A., and Jeanthon, C. (2003b). Vulcanithermus mediatlanticus gen. nov., sp nov., a novel member of the family Thermaceae from a deep-sea hot vent. Int. J. Syst. Evol. Microbiol. 53, 1143-1148. doi: 10.1099/ijs.0.02579-0.

Nesbo, C.L., Bradnan, D.M., Adebusuyi, A., Dlutek, M., Petrus, A.K., Foght, J., Doolittle, W.F., and Noll, K.M. (2012). Mesotoga prima gen. nov., sp nov., the first described mesophilic species of the Thermotogales. Extremophiles 16, 387-393. doi: 10.1007/s00792-012-0437-0.

Niharika, N., Moskalikova, H., Kaur, J., Sedlackova, M., Hampl, A., Damborsky, J., Prokop, Z., and Lal, R. (2013). Novosphingobium barchaimii sp nov., isolated from hexachlorocyclohexane-contaminated soil. Int. J. Syst. Evol. Microbiol. 63, 667-672. doi: 10.1099/ijs.0.039826-0.

Nolla-Ardevol, V., Strous, M., and Tegetmeyer, H.E. (2015). Anaerobic digestion of the microalga Spirulina at extreme alkaline conditions: biogas production, metagenome, and metatranscriptome. Front. Microbio. 6. doi: 10.3389/fmicp.2015.00597.

Pan, X.-C., Geng, S., Lv, X.-L., Mei, R., Jiangyang, J.-H., Wang, Y.-N., Xu, L., Liu, X.-Y., Tang, Y.-Q., Wang, G.-J., and Wu, X.-L. (2015). Defluviimonas alba sp nov., isolated from an oilfield. Int. J. Syst. Evol. Microbiol. 65, 1805-1811. doi: 10.1099/ijs.0.000181.

Rosenberg, E., Delong, E.F., Lory, S., Stackebrandt, E., and Thompson, F. (2014). The Prokaryotes: Other Major Lineages of Bacteria and The Archaea. Springer Berlin Heidelberg.

Salinas, M.B., Fardeau, M.L., Cayol, J.L., Casalot, L., Patel, B.K.C., Thomas, P., Garcia, J.L., and Ollivier, B. (2004). Petrobacter succinatimandens gen. nov., sp nov., a 
moderately thermophilic, nitrate-reducing bacterium isolated from an Australian oil well. Int. J. Syst. Evol. Microbiol. 54, 645-649. doi: 10.1099/ijs.0.02732-0.

Sohn, J.H., Kwon, K.K., Kang, J.H., Jung, H.B., and Kim, S.J. (2004). Novosphingobium pentaromativorans sp nov., a high-molecular-mass polycyclic aromatic hydrocarbondegrading bacterium isolated from estuarine sediment. Int. J. Syst. Evol. Microbiol. 54, 1483-1487. doi: 10.1099/ijs.0.02945-0.

Song, B.K., Palleroni, N.J., Kerkhof, L.J., and Haggblom, M.M. (2001). Characterization of halobenzoate-degrading. denitrifying Azoarcus and Thauera isolates and description of Thauera chlorobenzoica sp nov. Int. J. Syst. Evol. Microbiol. 51, 589-602.

Sun, W., and Cupples, A.M. (2012). Diversity of Five Anaerobic Toluene-Degrading Microbial Communities Investigated Using Stable Isotope Probing. Appl. Environ. Microbiol. 78, 972-980. doi: 10.1128/aem.06770-11.

Takai, K., Kobayashi, H., Nealson, K.H., and Horikoshi, K. (2003). Deferribacter desulfuricans sp nov., a novel sulfur-, nitrate- and arsenate-reducing thermophile isolated from a deep-sea hydrothermal vent. Int. J. Syst. Evol. Microbiol. 53, 839-846. doi: 10.1099/ijs.0.02479-0.

Takai, K., Moyer, C.L., Miyazaki, M., Nogi, Y., Hirayama, H., Nealson, K.H., and Horikoshi, K. (2005). Marinobacter alkaliphilus sp nov., a novel alkaliphilic bacterium isolated from subseafloor alkaline serpentine mud from Ocean Drilling Program Site 1200 at South Chamorro Seamount, Mariana Forearc. Extremophiles 9, 17-27. doi: 10.1007/s00792-004-0416-1.

Tiquia, S.M. (2010). Salt-adapted bacteria isolated from the Rouge River and potential for degradation of contaminants and biotechnological applications. Environ. Technol. 31, 967-978. doi: 10.1080/09593331003706226.

Urios, L., Agogue, H., Lesongeur, F., Stackebrandt, E., and Lebaron, P. (2006). Balneola vulgaris gen. nov., sp nov., a member of the phylum Bacteroidetes from the northwestern Mediterranean Sea. Int. J. Syst. Evol. Microbiol. 56, 1883-1887. doi: 10.1099/ijs.0.64285-0.

Urios, L., Intertaglia, L., Lesongeur, F., and Lebaron, P. (2008). Balneola alkaliphila sp nov, a marine bacterium isolated from the Mediterranean Sea. Int. J. Syst. Evol. Microbiol. 58, 1288-1291. doi: 10.1099/ijs.0.65555-0.

Wentzel, A., Ellingsen, T.E., Kotlar, H.-K., Zotchev, S.B., and Throne-Holst, M. (2007). Bacterial metabolism of long-chain $n$-alkanes. Appl. Microbiol. Biotechnol. 76, 12091221. doi: 10.1007/s00253-007-1119-1.

Zhang, Q., Wang, D., Li, M., Xiang, W.-N., and Achal, V. (2014). Isolation and characterization of diesel degrading bacteria, Sphingomonas sp and Acinetobacter junii from petroleum contaminated soil. Front. Earth Sci. 8, 58-63. doi: 10.1007/s11707-013-0415-6.

Zhang, Z., Hou, Z., Yang, C., Ma, C., Tao, F., and Xu, P. (2011). Degradation of $n$-alkanes and polycyclic aromatic hydrocarbons in petroleum by a newly isolated Pseudomonas aeruginosa DQ8. Bioresour. Technol. 102, 4111-4116. doi: 10.1016/j.biortech.2010.12.064. 